\title{
An Experimental Study of Complex-Offer Auctions from Wholesale Energy Markets
}

\author{
Rimvydas Baltaduonis ${ }^{1}$ \\ ${ }^{1}$ Gettysburg College, Gettysburg, Pennsylvania, USA \\ Correspondence: Rimvydas Baltaduonis, Department of Economics, Gettysburg College, 300 North Washington St., \\ Campus Box 391, Gettysburg, Pennsylvania 17325-1400, USA.
}

Received: April 10, 2014 Accepted: April 25, 2014 Available online: May 2, 2014

doi:10.11114/aef.v1i1.385 URL: http://dx.doi.org/10.11114/aef.v1i1.385

\begin{abstract}
A Payment Cost Minimization auction has been proposed as an alternative to the Offer Cost Minimization auction for use in wholesale electric power markets with an intention to lower procurement cost of electricity. Efficiency concerns have been raised for this proposal while assuming that the true production costs would be revealed to the auctioneer in a competitive market. Using an experimental approach, the study compares the performance of these two complex-offer auctions, controlling for the level of unilateral market power. The analysis finds that neither auction results in allocations that correspond to the true cost revelation. Two auctions perform similarly in terms of procurement cost and efficiency. Surprisingly, consumer prices in a competitive environment approach the prices of an environment with market power. It appears that the expected institutional effects for procurement cost and efficiency are greatly dominated by the effects of anti-competitive behavior due to the offer complexity and a cyclical nature of market demand.
\end{abstract}

Keywords: avoidable fixed cost, complex-offer auction, cyclical demand, efficiency, electricity, two-part pricing

\section{Introduction}

Billions of kilowatt-hours are traded daily in the U.S. wholesale electric power markets. Prices range from a tenth of a mill to 50 cents and more per $\mathrm{kWh}$. Under certain conditions, electric power generators even pay to produce power as reflected in prices below zero (Energy Information Administration [EIA], 2013). Many of these markets employ auctions that differ from other widely used quantity-price offer auctions in their offer complexity. Besides the quantities and the minimum prices, at which the electric power producers are willing to sell, the sellers may also declare their technical constraints and start-up fees that are designed to reimburse the fixed start-up costs of the generation plants. The start-up costs are avoidable fixed costs that create non-convex allocation problems. The generation contracts are daily allocated by a sealed-offer auction by using a computationally involved market-clearing algorithm. Besides applying a rule for offer selection, a market-clearing algorithm has to ensure that the system demand and reserve requirements are met over a particular time. In this paper, I compare the performance of two such algorithms by using a laboratory experiment.

An offer cost minimization (OCM) algorithm is currently used by independent system operators (ISOs) in the U.S. It relies on the traditional unit commitment approach (Note 1). The algorithm minimizes the total offered cost of electricity for a given demand as if all selected sellers would be paid their offered prices and fees. Sequentially, after the offers are selected, a uniform market-clearing price (MCP) is determined as the highest accepted price for that period. All selected sellers receive their individual start-up fees and the uniform MCP for the supplied electricity during that period.

Yan and Stern (2002) point out that the OCM algorithm does not ensure the lowest procurement cost of electricity to consumers for a given set of offers. This motivated Luh et al. (2006) to develop a payment cost minimization (PCM) algorithm as an alternative to the existing mechanism. The PCM algorithm minimizes the actual procurement cost of electricity simultaneously determining a MCP as the highest accepted price during that period. As in the OCM auction, the selected sellers would receive their individual start-up fees and the uniform MCP for the supplied electricity.

Non-convex optimization problems, similar to the OCM and the PCM algorithms, have been actively studied in electrical engineering for several decades because of potential savings in generation costs. The improvement of these 
mechanisms heavily depends on the assumption of complete information about the generation costs of electric power (Note 2). Even if such assumption might be practical in a regulated or state-owned system, there is no guarantee that complete information would be available to an ISO in a deregulated electricity market. One might hope that competitive forces in the market would induce the sellers to reveal their true generation costs. If so, the ISOs could continue to use the developed allocation mechanisms. Many analyses of the performance of the OCM and the PCM auctions are not exceptions and rely on the assumption of true production cost revelation (Alonso, Trias, Gaitan, \& Alba, 1999; Arroyo \& Conejo, 2002; Yan \& Stern, 2002; Luh et al., 2006). A few game theoretic studies include Knoblauch (2005), Baltaduonis (2007), Zhao, Luh, Yan, Stern, and Chang (2010). This paper employs an experimental approach to compare the two auctions. An economics experiment does not assume any strategic behavior and allows direct observation of the bidding activity.

In a game theoretic study, Knoblauch (2005) argues that the PCM auction should result in cheaper contract allocations given a competitive environment. Similarly, Baltaduonis (2007) demonstrates that in a competitive environment, the OCM auction should result in more production efficient allocations. These claims and a possible tradeoff between lower procurement cost and higher efficiency are put to an experimental test in this paper. The OCM and the PCM auctions can also be described as smart markets with two-part pricing. Durham, Rassenti, Smith, Van Boening, and Wilcox (1996) explore two-part pricing competition in a sealed-offer auction by conducting an experiment. Their auction uses a form of price discrimination in which active sellers receive exactly the fixed fee and unit price they asked for. Durham et al. (1996) find that in a setting with simulated buyers, this institution is effective in promoting full efficiency, but not quite immune to efficiency collapses. While both game theoretic studies and Durham et al. (1996) experiment model the market demand as static, this experimental study, as in Rassenti, Smith and Wilson (2003a; 2003b), simulates a cyclical nature of the daily demand for electricity. It appears that an interaction between a cyclical nature of the market demand and the offer complexity is a major factor determining performance of these auctions.

A comparison of the OCM and the PCM auctions would not be adequate without addressing a relationship between a degree of market power and auctions' performance. Given the inelastic nature of the market demand for electricity, it would be desirable to know if some trading rules are more effective in suppressing the exercise of market power. This study investigates such relationship by strictly controlling for the level of unilateral market power.

Direct theoretical studies of strategic behavior in complex-offer auctions frequently turn into intractable problems. This study complements the often inconclusive theoretical research by collecting some experimental data and tries to shed more light on possible strategic behavior in these auctions as researchers and oversight agencies continue to entertain policy recommendations for the electric power industry.

The remainder of the paper is organized as follows. Section 2 outlines the market environment in the experiment and describes the OCM and the PCM auctions. Section 3 presents the experimental design and procedures. Section 4 reports the findings. Section 5 concludes and suggests the direction of future research.

\section{Market Institution, Structure, and Environment}

To isolate the institutional effects of the strategically complex auctions, I examine a very simple environment relative to actual electric power systems: (i) transmission constraints are negligible; (ii) generators have no physical ramping rates; (iii) security reserves and other ancillary services to protect the system from outages are ignored; and (iv) a trading institution accepts flat offer curves for each generating unit. Such an environment is most comparable to day-ahead wholesale markets of observed power systems. The performance of the PCM auction is measured against the OCM auction in a stationary supply and cyclical demand environment with varying levels of unilateral market power.

\subsection{Auction Institution}

The sellers privately submit a schedule of offers, i.e. plant start-up fees and prices, for their production capacity for each pricing period of a day. The buyers submit a schedule of bids. Since active demand-side bidding is often absent in the naturally occurring spot markets for electricity, a computer is used to submit bids that perfectly reveal the demand at any point in time in the experiment (Note 3 ). The offers and the computerized bids are then sent to a market-clearing algorithm to allocate the production contracts for the next day.

Currently, the dominant practice in electricity spot markets is to employ uniform price auctions where each seller receives the same market price for the sold megawatts. The market price is usually the highest accepted price per megawatt among all the sellers. I retain these institutional features and put aside the discussion about "pay-as-offered" discriminatory price auctions (Note 4). In both the OCM and the PCM auctions, the sellers get paid uniform prices and their individual start-up fees.

In case of a uniform-price auction where sellers ask for fixed start-up fees, the mechanism of distributing these fees across the consumers is important. One way to do that is to divide the borne fees equally over the units dispatched during the period for which the extra generation capacity was called. The markup on the highest accepted offer price 
creates a spread between the uniform price that all sellers receive and the uniform price that all buyers pay. In this experiment, both the OCM and the PCM algorithms use this method to compute the buyer prices. The auctions are designed to sell the maximum amount of units where buyers' marginal willingness to pay is higher or equal to a buyer price.

\subsubsection{The OCM Auction (Note 5)}

The OCM algorithm minimizes the total offer costs of electricity, as if all selected sellers would be paid their offer prices and fees:

$$
\begin{aligned}
& \underset{q_{i}(t), x_{i}(t)}{\operatorname{Min}} \sum_{t=1}^{T} \sum_{i=1}^{N}\left(c_{i}(t) q_{i}(t)+f_{i}(t) x_{i}(t)\right) \\
& \text { subject to } \sum_{j=1}^{M} d_{j}(t)=\sum_{i=1}^{N} q_{i}(t) \quad \forall t=1, \ldots, T \text {, } \\
& q_{i}(t) \leq x_{i}(t) k_{i}(t) \quad \forall i=1, \ldots, N, \\
& q_{i}(t) \geq x_{i}(t) l_{i}(t) \quad \forall i=1, \ldots, N, \\
& x_{i}(t) \in\{0,1\} \quad \forall i=1, \ldots, N \text {. }
\end{aligned}
$$

where $i=1, \ldots, N$ indexes the generation plants;

$j=1, \ldots, M$ indexes the buyers;

$t=1, \ldots, T$ indicates the pricing periods during a day;

Offers submitted by sellers: $\left\{\begin{array}{l}c_{i}(t)=\text { price per unit asked for plant } i \\ f_{i}(t)=\text { start-up fee asked for plant } i \\ k_{i}(t)=\text { max capacity of plant } i \\ l_{i}(t)=\text { min capacity of plant } i\end{array}\right.$

Decision variables: $\left\{\begin{array}{l}q_{i}(t)=\# \text { units produced in plant } i \\ x_{i}(t)=\left\{\begin{array}{l}1 \text { if plant } i \text { is chosen to produce, } \\ 0 \text { if plant } i \text { is not chosen to produce. }\end{array}\right.\end{array}\right.$

After the offers are selected, a MCP is determined as the highest accepted price for each period $t$ :

$$
M C P(t)=\max \left\{c_{i}(t), \forall i \text { such that } q_{i}(t)>0\right\} .
$$

All selected sellers receive their individual start-up fees and the uniform MCPs for the supplied electricity.

\subsubsection{The PCM Auction}

The PCM algorithm minimizes the actual procurement cost of electricity, simultaneously determining a MCP as the highest accepted price for each period $t$.

$$
\begin{aligned}
& \operatorname{Min}_{q_{i}(t), x_{i}(t)} \sum_{t=1}^{T} \sum_{i=1}^{N}\left(M C P(t) q_{i}(t)+f_{i}(t) x_{i}(t)\right) \\
& \text { subject to } \sum_{j=1}^{M} d_{j}(t)=\sum_{i=1}^{N} q_{i}(t) \quad \forall t=1, \ldots, T, \\
& q_{i}(t) \leq x_{i}(t) k_{i}(t) \quad \forall i=1, \ldots, N, \\
& q_{i}(t) \geq x_{i}(t) l_{i}(t) \quad \forall i=1, \ldots, N, \\
& x_{i}(t) \in\{0,1\} \quad \forall i=1, \ldots, N \text {. }
\end{aligned}
$$


As in the OCM auction, the selected sellers receive their individual start-up fees and the uniform MCPs for the supplied electricity.

Tied offer combinations in the OCM auction are picked in a way that generates lower procurement cost. Tied offer combinations in the PCM auction are selected by giving priority to those sellers whose offer cost is lower. Such tie breaking gives the best performance chances to both auctions. To achieve similar tie breaking in real life applications would require additional computational power and time.

\subsection{Environment}

To contrast the performance of the OCM and the PCM auctions I first design an experimental market environment where unilateral market power is absent at all demand levels. I use this environment in what I call No Power treatments.

\subsubsection{No Power Treatments}

Each experimental day consists of four pricing periods: off peak period (low demand/night), shoulder period (medium demand/morning), peak period (high demand/ afternoon) and shoulder period (medium demand/ evening). Four pricing periods during a day are a simplification of the naturally occurring day-ahead electricity markets where separate prices are instituted hourly. Nevertheless, the cyclical dynamics of the demand are preserved.

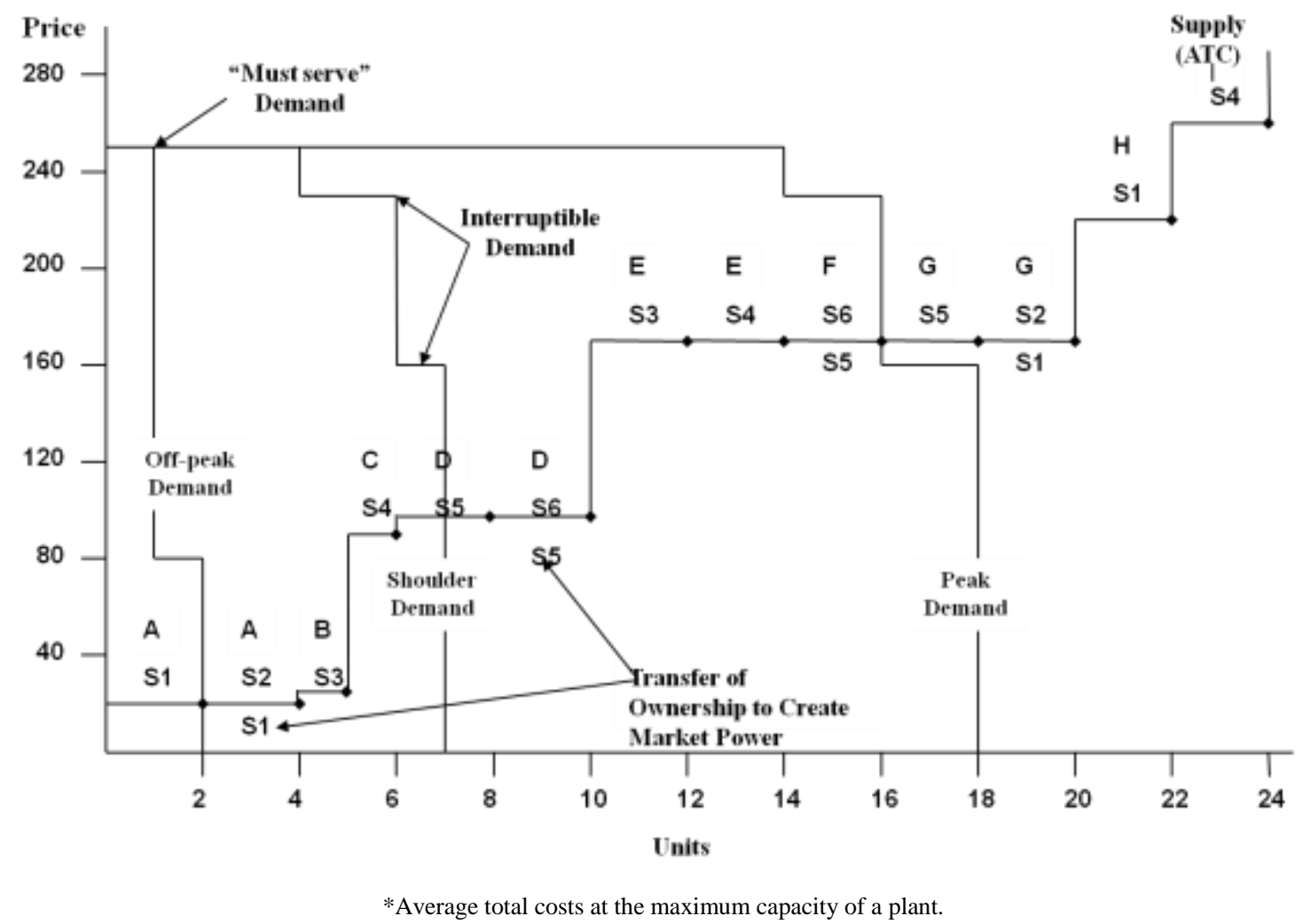

Figure 1. Market structure and design

Tables 1 and 2 as well as Figure 1 depict aggregate supply and demand in the environment. The second and third steps of the demand in Table 1 represent interruptible units of demand whereas the units on the first step at 250 are the "must serve" units. The level of "must serve" demand varied among three levels: 1 unit in the off-peak periods, 4 units during the shoulder periods, and 14 units during the peak periods.

Table 1. Demand schedules

\begin{tabular}{lccc}
\hline Demand & \multicolumn{3}{c}{ Quantity (demand values) } \\
\cline { 2 - 4 } & Step 1 & Step 2 & Step 3 \\
\hline Off-peak & $1(250)$ & $1(80)$ & N/A \\
Shoulder & $4(250)$ & $2(230)$ & $1(160)$ \\
Peak & $14(250)$ & $2(230)$ & $2(160)$ \\
\hline
\end{tabular}


Table 2. Average total costs (ATC) of production at max capacity (Cap.) by plant type

\begin{tabular}{lcccccc}
\hline Plant Type & Min Cap. & $\begin{array}{c}\text { Max } \\
\text { Cap. }\end{array}$ & $\begin{array}{c}\text { Start-up } \\
\text { Cost }\end{array}$ & $\begin{array}{c}\text { Per Unit } \\
\text { Cost }\end{array}$ & $\begin{array}{c}\text { ATC at Max } \\
\text { Cap. }\end{array}$ & Total Cap. \\
\cline { 2 - 7 } & Units & Units & $\$$ & \$/Unit & \$/Unit & Units \\
\hline$A(2)$ & 0 & 2 & 0 & 20 & 20 & 4 \\
$B(1)$ & 1 & 1 & 10 & 15 & 25 & 1 \\
$C(1)$ & 0 & 1 & 20 & 70 & 90 & 4 \\
$D(2)$ & 0 & 2 & 6 & 93 & 96 & 4 \\
$E(2)$ & 0 & 2 & 120 & 112 & 172 & 2 \\
$F(1)$ & 0 & 2 & 80 & 132 & 172 & 2 \\
$G(2)$ & 0 & 2 & 40 & 152 & 172 & 22 \\
$H(1)$ & 0 & 2 & 0 & 225 & 255 & 24 \\
$I(1)$ & 0 & 2 & 0 & 255 & & Total: \\
\hline
\end{tabular}

No Power market is comprised of six sellers denoted by an " $S$ " and an identification number. The sellers own 13 plants of nine types. The technical characteristics of each plant are presented in Table 2. Figure 1 presents the ownership of the plants. $S 1$ and $S 2$ own two low cost (type $A$ ) plants and two high cost plants (type $H$ and $G$ respectively). $S 3$ and $S 4$ own two high cost (type $E$ ) plants and respectively, one baseload (type $B$ ) plant and one intermediate cost (type $C$ ) plant. $S 4$ also owns a very high cost (type $I$ ) peak capacity plant with average total cost (ATC) exceeding even the resale value at the "must serve" level. Each $S 5$ and $S 6$ own one intermediate cost (type $D$ ) plant and one high cost (type $G$ and $F$ respectively) peak capacity plant. In a competitive equilibrium, the number of supplied units is 2 in the off-peak periods, 7 in the shoulder periods and 16 in the peak periods. The lower quantities of supplied units would be evidence of allocative inefficiencies. Note that an efficient allocation of contracts would never include $S 4$ 's plant $I$ and $S 1$ 's plant $H$.

The types and the distribution of the plants' ownership are designed to create a Bertrand-like competition between the marginal plants during every period of a day. In other words, at least two plants with identical production costs on the supply margins exist for each demand level. In a competitive bidding process, $S 1$ 's plant $A$ can be easily replaced by $S 2$ 's plant $A$ during an off-peak period and $S 5$ 's plant $D$ can be easily replaced by $S 6$ 's plant $D$ during the shoulder periods. Five plants with 10 units of total capacity and identical ATC compete to supply six units of peak demand.

In the context of capacity-constrained competitors, Holt (1989) defines market power as the ability to deviate profitably and unilaterally from the competitive outcome. The competitive outcome usually implies that a MCP equals the marginal cost and that the marginal sellers earn zero or close to zero economic profits. In the complex-offer auctions, the notion of a competitive outcome cannot be summarized by a MCP approaching marginal cost. A seller asking a price that is equal to the marginal cost can still profitably exercise her market power by charging a higher fee than the actual start-up cost. A deadweight loss can occur if this action reduces the number of units traded. To control for such unilateral market power, the designed marginal plants have incentives to submit offers that do not exceed the actual production costs of the marginal units at any given period of the demand cycle. However, the asked fees and seller prices do not necessarily need to be in exact proportions of the actual production costs.

Consider the OCM auction for an illustration. Take a shoulder 1 period. Each $S 5$ and $S 6$ owns a marginal intermediate cost plant that competes to supply the marginal seventh unit to the market. Either plant can generate this marginal unit at a cost of 99 [6+93]. If a seller offers to supply the unit at a cost higher than 99, the other seller would be able to undercut the offer by either lowering the fixed fee or lowering the offered seller price. Therefore, in a competitive offer of $S 5$ or $S 6$, a sum of the start-up fee and the price per unit could not exceed 99. There exists a multiplicity of pure strategy Nash equilibria in shoulder 1 period with the upper bound for competitive buyer price at 155 . The marginal plants earn zero economic profits in all of them. The upper bound would be reached if two marginal generators asked prices of 99 with zero start-up fees, and if other low cost generators $A, B$ and $C$ decided to recover their costs exclusively through fixed fees, i.e. submitting offers of zero prices with start-up fees equal to $98(<99)$ for one-unit capacity plants and $196(=2 \times 98)$ for two-unit capacity plants. The OCM auction would select these offers before the marginal offers of 99 . As discussed above, the amount of fees would be used to mark-up a buyer price for shoulder 1 period $[99+(98 \times 4 \div 7)=155]$. As in other competitive equilibria, marginal generators $S 5$ and $S 6$ would earn zero economic profits. If either of them sold a unit at a positive profit, the other seller could undercut the offer and win the contract.

The costs for the marginal units for other periods are 20 in the off-peak periods, 172 in the peak periods and 93 in shoulder 2 periods. The unique competitive buyer prices are 20 for the off-peak and 93 for shoulder 2 periods. A competitive buyer price for the peak periods is bounded from above at 230 by step 2 of the market demand. Peak periods, similar to shoulder 1 periods, have a multiplicity of pure strategy Nash equilibria in which all marginal generators earn zero economic profits. 
Note that the shoulder periods before and after the peak have the same demand and supply structures. However, most of the plants are not idle after peak periods. They do not incur start-up costs and do not receive start-up fees to continue production during shoulder 2 periods. For this reason, competition during shoulder 2 periods happens solely through seller price offers. Consequently, the competitive price in shoulder 2 periods equals to the marginal cost (93). A comparison of shoulder 1 and shoulder 2 periods provides an interesting perspective on competition with and without avoidable fixed costs.

The bounds for the competitive buyer prices are identical in both the OCM and the PCM auctions. This feature is due to the identical offer structures and due to the presence of Bertrand-like competitors at every demand level. In a three-supplier market, Knoblauch (2005) shows that a Bertrand competition game results in a competitive outcome leading to cheaper contract allocations in the PCM auction. Baltaduonis (2007) extends Knoblauch's analysis to efficiency and shows that the OCM auction results in more efficient allocations. Therefore, the presence of three suppliers at the margins of off-peak and shoulder demand levels is not accidental. It resembles market environments discussed by Knoblauch and Baltaduonis. When designing the experiment I was curious if two auctions would dominate each other as expected with respect to procurement cost and efficiency given a more strategically rich environment with a cyclical market demand.

\subsubsection{Power Treatments}

A comparison of the OCM and the PCM auctions would not be adequate without addressing a relationship between a degree of market power and auctions' performance. In the experiment, a seller is said to be able to exert market power if, for a given distribution of capacity ownership, a seller profitably and unilaterally can submit an offer schedule above his plants' costs (or equivalently withdraw some generating capacity) such that the market price rises above the competitive level.

Davis and Holt (1994), and Rassenti et al. (2003a; 2003b) create market-power incentives in the simple-offer laboratory markets by reallocating production capacities while keeping the market supply unchanged. I adopt this approach (Note 6).

Market power can be raised merely by transferring the ownership of $S 2$ 's and $S 6$ 's plants to $S 1$ and $S 5$, respectively. The reallocation of plants' ownership gives the power to $S 1$ and $S 5$ to charge for the marginal units more than their actual production costs while earning positive economic profits. In the Power treatments, $S 1$ and $S 5$ can unilaterally and profitably increase their offers for the off-peak and shoulder periods regardless of the auction.

For example, during an off-peak period, $S 1$ is basically guaranteed to sell at least one unit as long as the buyer price does not exceed step 2 of the demand curve (80). Instead of competing with $S 3$ 's and her own plants, $S 1$ can profitably withdraw three units of production capacity (or equivalently raise the offers for those units). Many stable pure strategy Nash equilibria exist with different profit shares depending on S3's offer. Notice that by withdrawing relatively cheaper capacity from the market, $S 1$ also causes production inefficiency.

Similarly, during a shoulder period, $S 5$ can profitably increase the offer above the actual production cost. As long as the buyer price does not exceed step 3 of shoulder demand (160), $S 5$ would earn a positive economic profit. The size of the profit would depend on the offers of S1, S3 and S4. On the other hand, during a shoulder 2 period (when most plants are not eligible for start-up fees), $S 5$ should set the price at exactly 160 and earn profit of 67 . In shoulder periods, the production efficiency is preserved even when market power is exercised.

Note, during the peak demand all unilateral deviations from competitive offers are unprofitable in both No Power and Power treatments.

Holt (1989) points out that the notion of unilateral market power can be sensitive to the distinguishing characteristics of market institutions. He notes that the effects of institutions often seem to dominate the effects of structural characteristics of the market. In the designed experiment, the structural features of market power suggest identical incentives for both the OCM and the PCM auctions. Furthermore, if all sellers would truthfully submit their actual production costs, the amount of exchanged units during each period of a day would be the same, the total procurement cost of electricity during the day would be the same and the total production cost of electricity would be barely one percent higher under the PCM auction. An experiment could reveal whether institutional effects for suppressing or fostering market power exist.

\section{Experimental Design and Procedures}

To compare how behavior and market performance differ in the OCM and the PCM auctions, I conducted 16 market sessions using undergraduate students at George Mason University. The paper reports the experimental data from the completed $2 \times 2$ design with four sessions in each treatment: OCM/No Power, PCM/No Power, OCM/Power and PCM/Power. Each session lasted 53 trading days (Note 7). The dataset discussed in this paper includes a total of 848 trading days. Each session lasted approximately 90 minutes. 
The subjects in each market were provided with complete information about the market supply structure. Plants minimum and maximum production capacity, start-up cost, cost per unit and the ownership of all plants were public information. Information about demand however, was not available to the subjects. The situation was framed as a market for identical product to avoid the use of possibly intimidating or confusing electric power jargon. The instructions informed the subjects that the costs and production capacities for each seller would not change during the experiment, but that the purchased quantities of the product would vary over the course of a day. In particular, the instructions indicated that the computer will purchase "low" amounts of product for the first quarter of a day, "medium" amounts for the second quarter of a day, "high" amounts for the third quarter of a day and "medium" amounts for the fourth quarter of a day. The subjects did not know the number of trading days in advance. The instructions were read aloud in the beginning of each session.

A subject had 75 seconds to submit an offer for each day (Note 8). An exception was made for the first day offers. The sellers could take as much time as they needed to formalize their initial offers. Once the last seller submitted her offer for the first day, the following trading days were limited to 75 seconds. The offers were automatically filled in with the offer information from the previous trading day. However, a seller could revise her offer at any time within the 75 second period. An offer indicated the prices, start-up fees and quantities of the product that a seller was willing to supply from a particular plant over the course of the following day. The subjects could not alter the minimum and maximum quantities of the offer (Note 9). These quantities were set equal to the minimum and maximum capacities of a plant. The subjects could still effectively withdraw the capacity from the market by asking extremely high prices for those capacity units. Thus, a seller had to decide on the price and the start-up fee for each plant and for each quarter of the upcoming day (Note 10). The instructions pointed out that the actual market price may be higher than their offered price and that all sellers would receive the same market price if their offers were selected. The sellers received start-up fees only for the periods when their plant had to be started. In the beginning of each day all plants were idle.

At the end of the trading day, all offers were sent to the computerized market coordinator. A market-clearing algorithm was applied and the results of a sealed-offer auction were sent back to the sellers. Each seller could see how many units she sold, what the MCP for each period was and what profit/loss she earned on every owned capacity unit during each period of a day. The screens also displayed a history of the market prices from the past 10 days and the sold quantities during each quarter of the last day. The amount of paid fees was not public information (Note 11).

Subjects were paid $\$ 7$ for showing up on time for the sessions. In addition to this show-up payment, the average earnings per subject for the data reported here was $\$ 21.47$.

\section{Results}

In the No Power treatments, the OCM and the PCM auctions on average extract respectively 92 percent and 94 percent of maximum total surplus. The auctions capture 90 percent of the maximum surplus in the Power treatments.

To present how the captured total surplus is allocated among buyers and sellers, and how volatile the allocation is, Figures 2-5 depict the buyer prices in each session of four treatments. The last 17 days of the data are grouped by level of demand (quarter) then sequenced by how the demand varied over a market day: off-peak, shoulder 1, peak and shoulder 2.

I evaluate the results with respect to the true cost revelation. The outcome of the true cost revelation is particularly interesting in the electricity markets because the design and the engineering of these complicated market systems often start with the assumption of the true cost revelation. As an attempt to control for the convergence of the bidding behavior, I focus on the last 17 market days (1/3 of all days) in each session. In Figures 2-5, the outcome of the perfectly revealed costs is shown as a solid line. The dotted line represents the value of the nearest unit of interruptible demand. The prices up to the dotted line are $100 \%$ efficient with respect to allocation.

As Figures 2-5 suggest, sellers generally supplied the efficient equilibrium quantity of the product during all periods of a day, but neither treatment succeeded completely. Due to a higher buyer price for the efficient amount than buyers' maximum willingness to pay, the demand had to be interrupted on five occasions (out of possible $272=17$ days $\times$ 4quarters $\times 4$ sessions) in the OCM/No Power treatment. Fourteen interruptions happened during the OCM/Power treatment and four during the $P C M / N o$ Power treatment. Demand interruptions were more noticeable in the $P C M /$ Power treatment. They occurred on 85 occasions. Interestingly, not a single occasion existed when the demand had to be interrupted during the shoulder 2 periods regardless of a treatment.

In what follows, the experimental results are summarized as a series of six findings. In addition to the qualitative results displayed in the figures, I analyze the data using a mixed-effects model for repeated measures on each of several sessions using different subjects. The results from estimating this model for the buyer prices by level of demand are given in Table 3. The dependent variable in this case is the difference between the observed buyer price (Price) and the buyer price from the OCM auction when the production costs are perfectly revealed by the sellers $\left(P^{t}\right)$. The OCM 
auction is chosen as a benchmark institution in the regressions to represent the status quo. The treatment effects (Power and $P C M$ ) are modeled as (zero-one) fixed effects, whereas the sessions are modeled as random effects, $e_{i}$. As mentioned above, the experimental days are divided into three equal groups to capture the effects like learning over time. In the model, the data from the First and Second groups (days 1-18 and 19-36, respectively) are identified by (zero-one) dummy variables. Specifically, the estimated model is as follows:

$$
\begin{gathered}
\text { Price }_{i j} P^{t}=\mu+e_{i}+\beta_{1} \text { PCM }_{i}+\beta_{2} \text { Power }_{i}+\beta_{3} \text { PCM }_{i} \times \text { Powe }_{i}+\beta_{4} \text { First }_{i}+\beta_{5} \text { Second }_{i}+\beta_{6} \text { PCM }_{i} \times \text { First }_{i}+ \\
+\beta_{7} \text { PCM }_{i} \times \text { Second }_{i}+\beta_{8} \text { Power }_{i} \times \text { First }_{i}+\beta_{9} \text { Power }_{i} \times \text { Second }_{i}+\beta_{10} \text { PCM }_{i} \times \text { Power }_{i} \times \text { First }_{i}+\beta_{11} \text { PCM }_{i} \times \text { Power }_{i} \times \text { Second }_{i}+\varepsilon_{i j}
\end{gathered}
$$

where the sessions are indexed by $i=1, \ldots, 16$ and the repeated market days by $j=1, \ldots, 53 . e_{i} \sim N\left(0, \sigma_{l}^{2}\right)$ and $\varepsilon_{i j} \sim N\left(0, \sigma_{2, i}^{2}\right)$.

Finding 1. The OCM and the PCM auctions do not elicit true production cost revelation in the periods when start-up costs are relevant.

Figures 2-5 illustrate that the outcomes of perfectly revealed costs do not dominate. Both auctions produce buyer prices that are much higher than the prices corresponding to the true cost revelation during all three periods when new plants need to be started, i.e. in off-peak, shoulder 1 and peak periods. The buyer prices are higher in both No Power and Power treatments. An exception is shoulder 2 prices. In shoulder 2 periods, when most of the plants are already operating and therefore, not eligible for the start-up fees, the sellers compete purely on prices and are more likely to approach the true cost revelation outcome.

These qualitative observations are supported by estimates from the mixed-effects model in Table 3 . The OCM/No Power treatment significantly raises prices above the true cost revelation level by 18.53 ( $p$-value=0.0108) and 57.17 ( $p$-value $<0.0001)$ experimental dollars in shoulder 1 and peak periods. The PCM/No Power treatment significantly raises prices above the true cost revelation level by 17.08 ( $p$-value $=0.0043), 17.08$ ( $p$-value $=0.0368$ ) and 60.04 ( $p$-value $<0.0001)$ in off-peak, shoulder 1 and peak periods respectively (Note 12). The Power treatments mirror this phenomenon. On the other hand, the prices in shoulder 2 periods are not significantly higher than the true cost revelation outcome ( $p$-value $=0.4345$ for OCM/No Power, $p$-value $=0.3204$ for PCM/No Power)

Complex-offer and non-convex optimization algorithms are constantly being developed and proposed for wholesale power markets. The improvements of these market mechanisms usually rely on the assumption that the actual generation costs would be revealed to the auctioneer in a competitive environment. Finding 1 suggests that this theoretical assumption might be unwarranted even in a competitive environment.

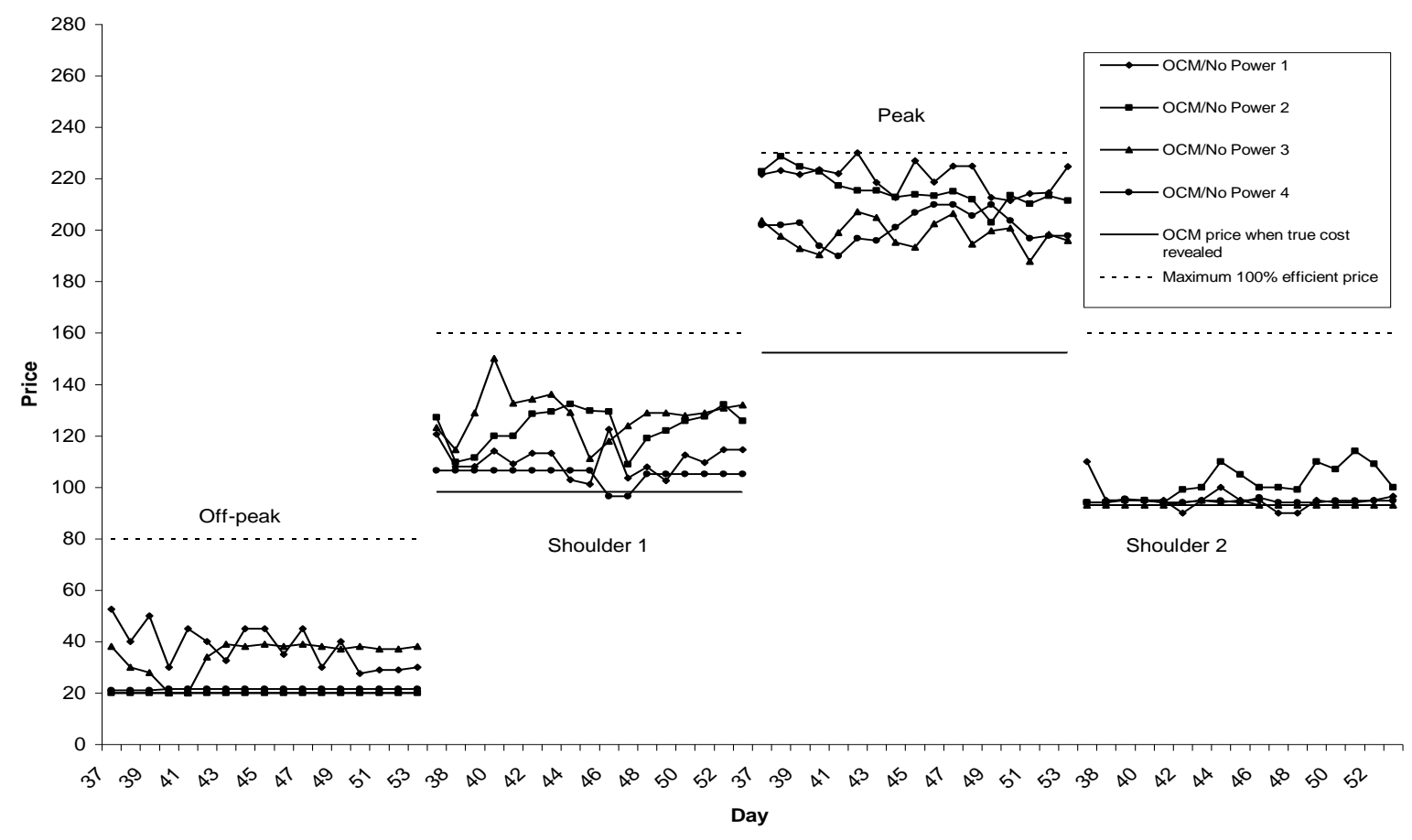

Figure 2. OCM/No Power buyer prices by level of demand for the last 17 market days in each session 


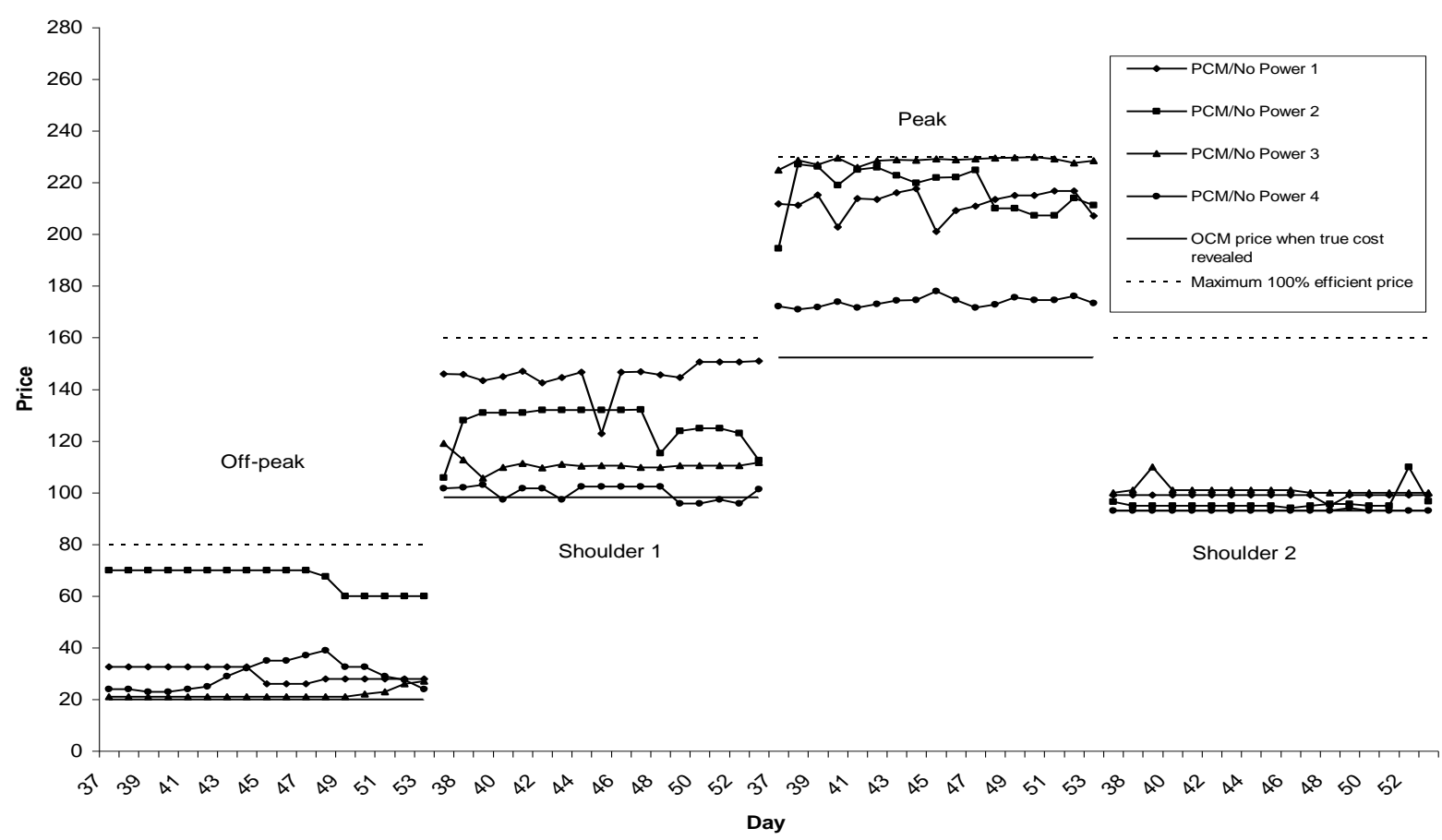

Figure 3. PCM/No Power buyer prices by level of demand for the last 17 market days in each session

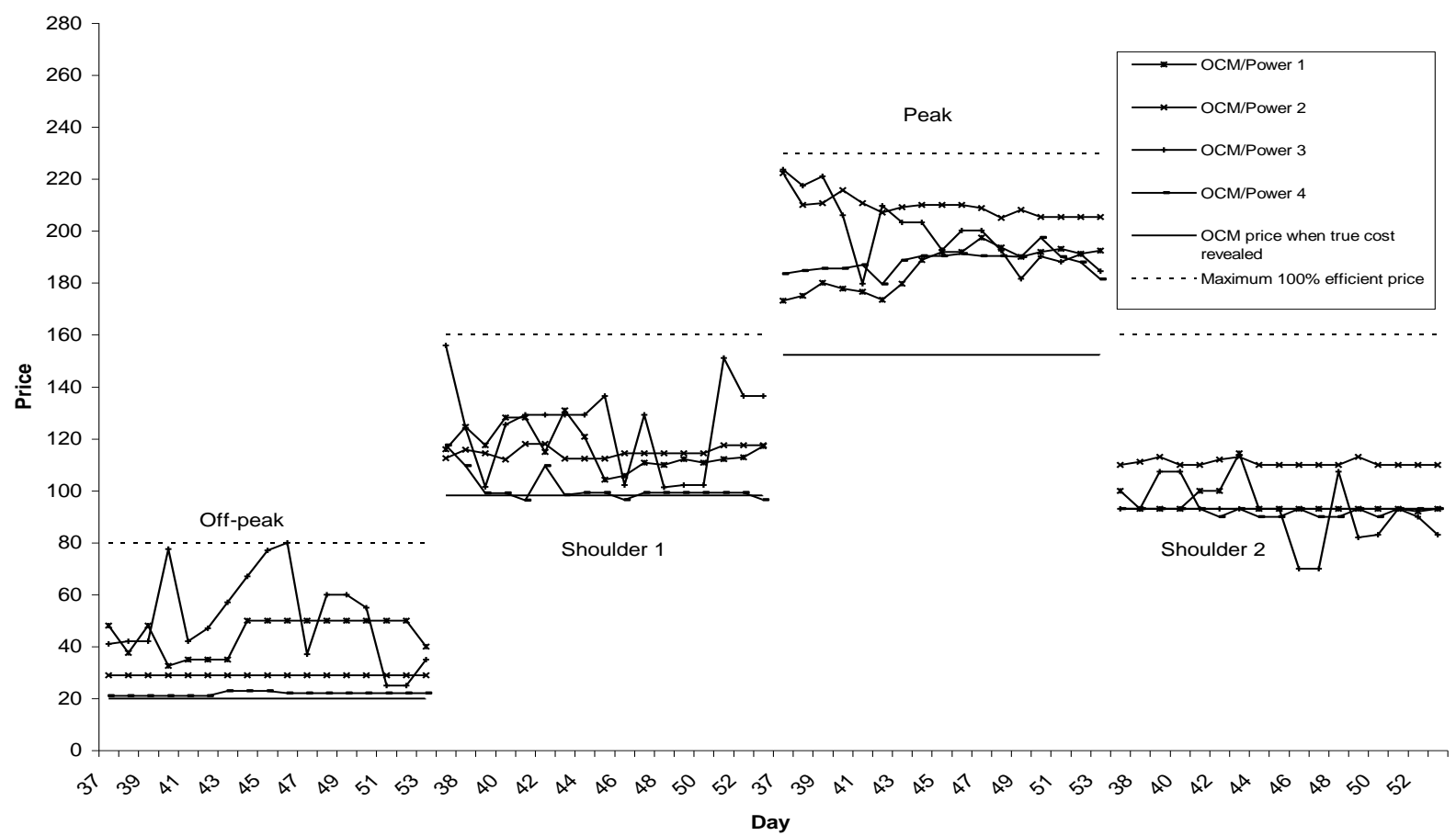

Figure 4. OCM/Power buyer prices by level of demand for the last 17 market days in each session 


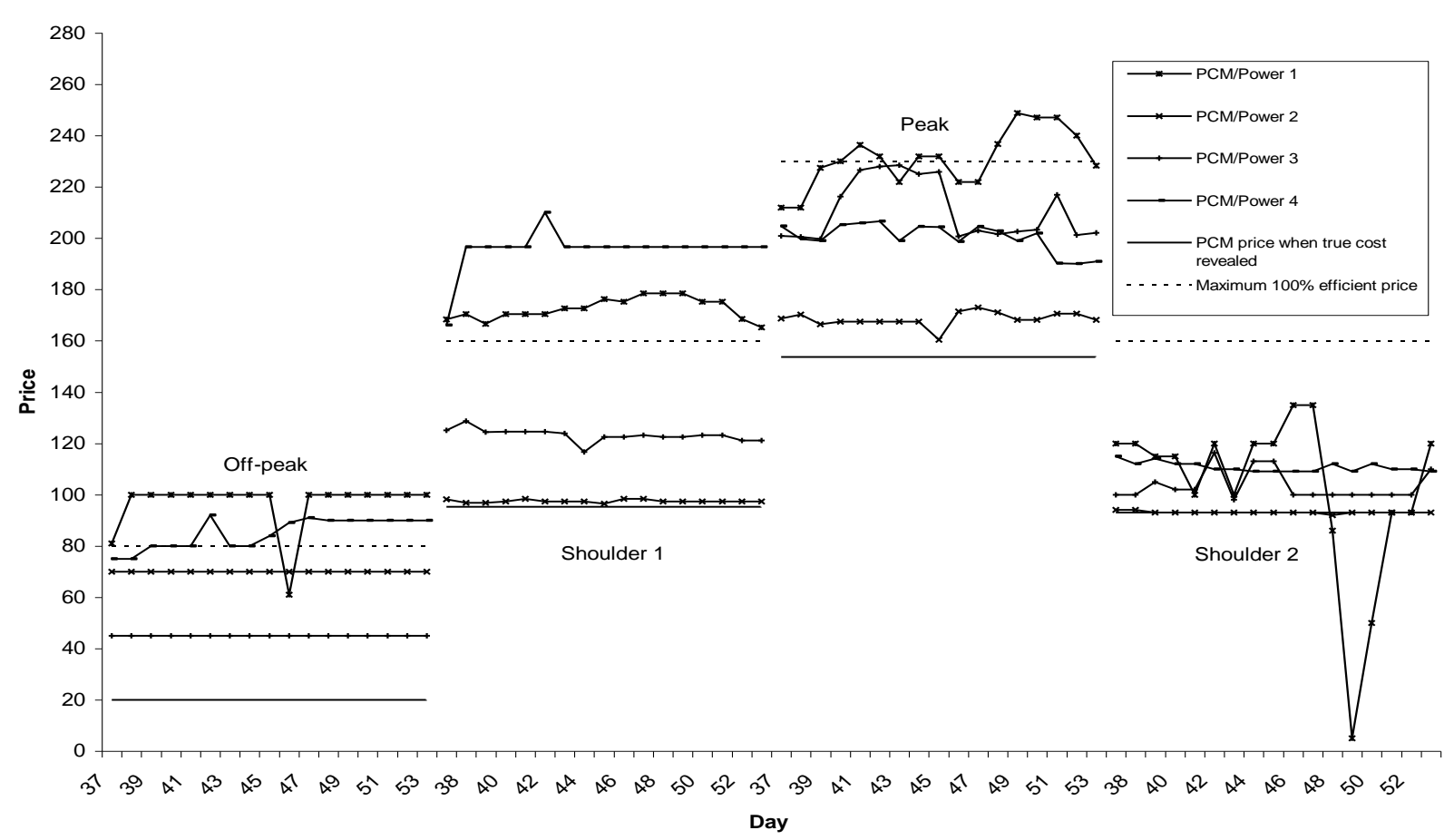

Figure 5. PCM/Power buyer prices by level of demand for the last 17 market days in each session

Finding 2. Ceteris paribus, changing the auction institution from OCM to PCM does not significantly lower buyer prices in any period.

Figures $2 \& 3$ suggest similar levels of buyer prices in OCM/No Power and PCM/No Power treatments. In addition, the estimates for the PCM/No Power treatment in the mixed-effects model are statistically insignificant ( $p$-values $=0.2736$, 0.8724, 0.7957 and 0.8338 for off-peak, shoulder 1, peak and shoulder 2 periods). Moreover, buyer prices are not significantly different across the auctions in the Power treatments either, with an exception of off-peak periods ( $p$-values $=0.0117,0.3277,0.9982$ and 0.5775$)$. In off-peak periods, the PCM auction significantly raises prices above the OCM level.

Finding 2 does not confirm an expectation that the PCM auction will be more effective in eliciting outcomes with lower buyer prices. The anticipated institutional effects of the PCM auction in arriving at lower cost Nash equilibria are absent.

Finding 3. Ceteris paribus, the Power treatment has no effect on buyer prices in the OCM and the PCM auctions.

Figure 2 versus Figure 4, and Figure 3 versus Figure 5 contrast buyer prices in No Power and Power treatments for both auctions. The estimates for the OCM/Power treatment in the mixed-effects model are statistically insignificant ( $p$-values $=0.2223,0.9036,0.3457$ and 0.5655 for off-peak, shoulder 1 , peak and shoulder 2 periods). The estimates are also not significant for the PCM/Power treatment in all periods but off-peak ( $p$-values $=0.0085,0.3058,0.2403$ and 0.3461) (Note 13).

Finding 1 and Finding 3 raise a question why Bertrand-like competitors do not undercut their counterparts causing buyer prices to drop to the competitive levels or at least to lower levels than in the Power treatments. Figure 6 presents the average profits of the marginal plants for each period of a day. It is evident that marginal plants earn positive and significant economic profits in all but shoulder 2 periods. The differences between all treatments are statistically insignificant. Interestingly, it also appears that some Bertrand-like competitors who do not sell the product accumulate higher profits than their counterparts who sell.

It turns out that low and intermediate cost plants that do not sell during the off-peak and shoulder 1 periods are successful in charging much higher fees to be started a period later. Since these plants need to be started for higher demand periods, they can offer high start-up fees for those periods and still undercut higher cost plants. For instance, in session 2 of the OCM/No Power treatment, S3 is able to charge 80 (true start-up cost=10) experimental dollars to start his low cost plant during the intermediate demand periods. Similarly, during the intermediate demand periods of session 1 of the $P C M /$ No Power treatment, $S 1$ is able to charge 195 (true start-up cost=0) to start her low cost plant. These big 
Table 3. Estimates of the linear mixed effects model of treatment effects for the buyer prices (Note 14)

\begin{tabular}{|c|c|c|c|c|c|c|}
\hline \multicolumn{7}{|c|}{$\begin{array}{l}\text { Price }_{i j}-P^{t}=\mu+e_{i}+\beta_{1} \text { PCM }_{i}+\beta_{2} \text { Power }_{i}+\beta_{3} \text { PCM }_{i} \times \text { Power }_{i}+\beta_{4} \text { First }_{i}+\beta_{5} \text { Second }_{i}+\beta_{6} \text { PCM }_{i} \times \text { First }_{i}+\beta_{7} P C M_{i} \times \text { Second }_{i}+\beta_{8} \text { Power }_{i} \times \\
\text { First }_{i}+\beta_{9} \text { Power }_{i} \times \text { Second }_{i}+\beta_{10} \text { PCM }_{i} \times \text { Power }_{i} \times \text { First }_{i}+\beta_{11} P C M_{i} \times \text { Power }_{i} \times \text { Second }_{i}+\varepsilon_{i j}, \quad e_{i} \sim N\left(0, \sigma_{l}^{2}\right) \text { and } \varepsilon_{i j} \sim N\left(0, \sigma_{2, i}^{2}\right)\end{array}$} \\
\hline & Estimate & Std. Error & Degrees of Freedom & $\mathrm{H}_{\mathrm{a}}$ & t-statistic & p-value \\
\hline \multicolumn{7}{|l|}{ Off-peak } \\
\hline $\boldsymbol{\mu}$ & 7.38 & 5.99 & 824 & $\mu>0$ & 1.23 & 0.1092 \\
\hline PCM & 9.70 & 8.46 & 12 & $\beta_{1} \neq 0$ & 1.15 & 0.2736 \\
\hline Power & 10.98 & 8.53 & 12 & $\beta_{2} \neq \mathbf{0}$ & 1.29 & 0.2223 \\
\hline PCM×Power & 15.88 & 12.07 & 12 & $\beta_{3} \neq 0$ & 1.32 & 0.2131 \\
\hline First & -6.71 & 1.22 & 824 & $\beta_{4} \neq 0$ & -5.51 & $<.0001$ \\
\hline Second & -2.72 & 1.22 & 824 & $\beta_{5} \neq 0$ & -2.23 & 0.0262 \\
\hline PCM $\times$ First & 4.25 & 1.46 & 824 & $\beta_{6} \neq 0$ & 2.91 & 0.0037 \\
\hline $\mathrm{PCM} \times$ Second & 1.04 & 1.46 & 824 & $\beta_{7} \neq 0$ & 0.72 & 0.4748 \\
\hline Power×First & 6.39 & 1.97 & 824 & $\beta_{8} \neq 0$ & 3.24 & 0.0012 \\
\hline Power×Second & 3.29 & 1.97 & 824 & $\beta_{9} \neq 0$ & 1.67 & 0.0952 \\
\hline PCM $\times$ Power $\times$ First & -7.41 & 2.62 & 824 & $\beta_{10} \neq 0$ & -2.83 & 0.0047 \\
\hline PCM $\times$ Power $\times$ Second & 2.62 & 2.62 & 824 & $\beta_{11} \neq 0$ & 1.00 & 0.3166 \\
\hline \multicolumn{7}{|l|}{ Shoulder 1} \\
\hline$\mu$ & 18.53 & 8.05 & 824 & $\mu>0$ & 2.30 & 0.0108 \\
\hline РCM & -1.86 & 11.33 & 12 & $\beta_{1} \neq 0$ & -0.16 & 0.8724 \\
\hline Power & -1.42 & 11.45 & 12 & $\beta_{2} \neq \mathbf{0}$ & -0.12 & 0.9036 \\
\hline PCM $\times$ Power & 13.58 & 16.14 & 12 & $\beta_{3} \neq 0$ & 0.84 & 0.4164 \\
\hline First & -7.98 & 2.17 & 824 & $\beta_{4} \neq 0$ & -3.68 & 0.0003 \\
\hline Second & -1.61 & 2.17 & 824 & $\beta_{5} \neq 0$ & -0.74 & 0.4595 \\
\hline PCM×First & 15.69 & 2.44 & 824 & $\beta_{6} \neq 0$ & 6.44 & $<.0001$ \\
\hline $\mathrm{PCM} \times$ Second & 3.26 & 2.44 & 824 & $\beta_{7} \neq 0$ & 1.34 & 0.1818 \\
\hline Power×First & 0.26 & 3.33 & 824 & $\beta_{8} \neq 0$ & 0.08 & 0.9375 \\
\hline Power $\times$ Second & 8.65 & 3.33 & 824 & $\beta_{9} \neq 0$ & 2.59 & 0.0096 \\
\hline PCM $\times$ Power $\times$ First & -5.68 & 3.55 & 824 & $\beta_{10} \neq 0$ & -1.60 & 0.1099 \\
\hline PCM $\times$ Power $\times$ Second & -9.11 & 3.55 & 824 & $\beta_{11} \neq 0$ & -2.57 & 0.0105 \\
\hline \multicolumn{7}{|l|}{ Peak } \\
\hline $\boldsymbol{\mu}$ & 57.17 & 7.67 & 824 & $\boldsymbol{\mu}>\mathbf{0}$ & 7.45 & $<.0001$ \\
\hline PCM & 2.87 & 10.84 & 12 & $\beta_{1} \neq 0$ & 0.26 & 0.7957 \\
\hline Power & -10.66 & 10.86 & 12 & $\beta_{2} \neq \mathbf{0}$ & -0.98 & 0.3457 \\
\hline PCM×Power & -2.84 & 15.41 & 12 & $\beta_{3} \neq 0$ & -0.18 & 0.8567 \\
\hline First & -2.09 & 1.85 & 824 & $\beta_{4} \neq 0$ & -1.14 & 0.2565 \\
\hline Second & 4.37 & 1.85 & 824 & $\beta_{5} \neq 0$ & 2.36 & 0.0183 \\
\hline PCM $\times$ First & -6.54 & 2.50 & 824 & $\beta_{6} \neq 0$ & -2.62 & 0.0090 \\
\hline $\mathrm{PCM} \times$ Second & -7.72 & 2.50 & 824 & $\beta_{7} \neq 0$ & -3.09 & 0.0021 \\
\hline Power×First & -8.37 & 2.75 & 824 & $\beta_{8} \neq 0$ & -3.05 & 0.0024 \\
\hline Power $\times$ Second & -4.00 & 2.75 & 824 & $\beta_{9} \neq 0$ & -1.46 & 0.1453 \\
\hline PCM $\times$ Power $\times$ First & 11.00 & 4.10 & 824 & $\beta_{10} \neq 0$ & 2.68 & 0.0074 \\
\hline PCM $\times$ Power $\times$ Second & 6.56 & 4.10 & 824 & $\beta_{11} \neq 0$ & 1.60 & 0.1099 \\
\hline \multicolumn{7}{|l|}{ Shoulder 2} \\
\hline $\boldsymbol{\mu}$ & 0.66 & 4.00 & 824 & $\mu>0$ & 0.17 & 0.4345 \\
\hline PCM & 1.22 & 5.67 & 12 & $\beta_{1} \neq 0$ & 0.21 & 0.8338 \\
\hline Power & 3.45 & 5.84 & 12 & $\beta_{2} \neq \mathbf{0}$ & 0.59 & 0.5655 \\
\hline PCM×Power & 2.14 & 8.16 & 12 & $\beta_{3} \neq 0$ & 0.26 & 0.7975 \\
\hline First & -0.51 & 0.28 & 824 & $\beta_{4} \neq 0$ & -1.79 & 0.0733 \\
\hline Second & -0.31 & 0.28 & 824 & $\beta_{5} \neq 0$ & -1.10 & 0.2723 \\
\hline PCM×First & 10.88 & 1.25 & 824 & $\beta_{6} \neq 0$ & 8.72 & $<.0001$ \\
\hline $\mathrm{PCM} \times$ Second & 3.67 & 1.25 & 824 & $\beta_{7} \neq 0$ & 2.94 & 0.0034 \\
\hline Power×First & -3.22 & 2.15 & 824 & $\beta_{8} \neq 0$ & -1.50 & 0.1342 \\
\hline Power $\times$ Second & 0.24 & 2.15 & 824 & $\beta_{9} \neq 0$ & 0.11 & 0.9102 \\
\hline PCM×Power $\times$ First & -5.25 & 2.53 & 824 & $\beta_{10} \neq 0$ & -2.08 & 0.0383 \\
\hline PCM $\times$ Power $\times$ Second & -3.67 & 2.53 & 824 & $\beta_{11} \neq 0$ & -1.45 & 0.1468 \\
\hline
\end{tabular}




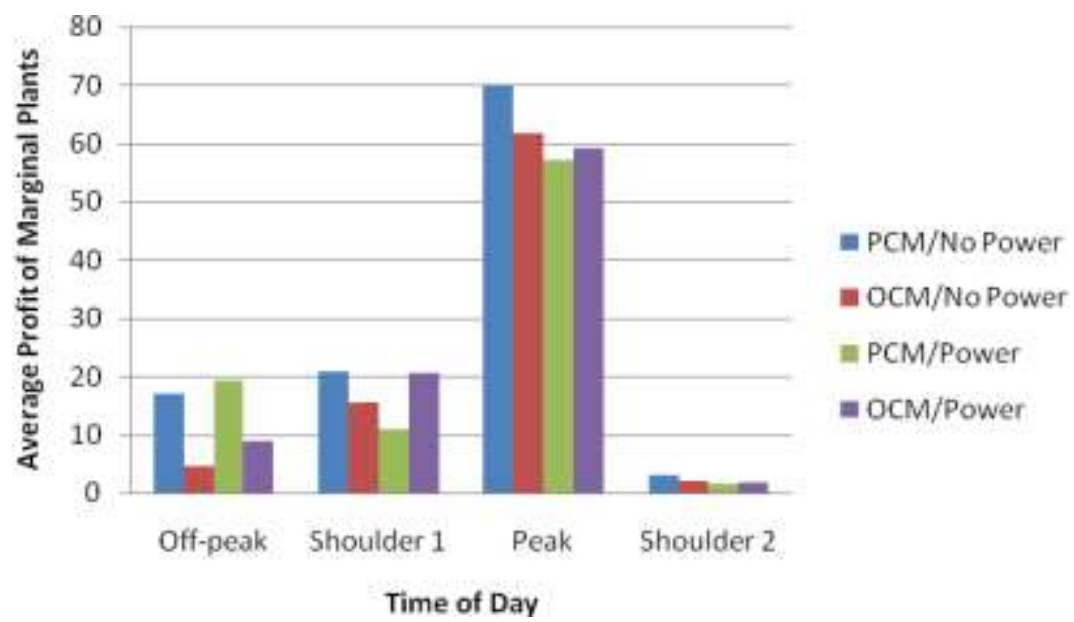

Figure 6. Average profits of marginal plants by treatment for the last 17 market days

payoffs from fees do not leave many incentives to compete for the contracts during the lower demand periods. Indeed, such withholding of capacity for higher demand periods explains why competition is so weak in No Power treatments. The Power treatments exhibit similar offer strategies. In session 1 of the PCM/Power treatment, $S 4$ is constantly able to charge 500 (true start-up cost $=6$ ) experimental dollars to start an intermediate cost plant during the peak periods.

Table 4. Estimates of the linear mixed effects model of treatment effects for the income from fees and seller prices (Note 14)

\begin{tabular}{|c|c|c|c|c|c|c|}
\hline \multicolumn{7}{|c|}{$\begin{array}{c}\text { FeeInc }_{i j}-\text { FeeInc }^{t}=\mu+e_{i}+\beta_{1} \text { PCM }_{i}+\beta_{2} \text { Power }_{i}+\beta_{3} P C M_{i} \times \text { Power }_{i}+\beta_{4} \text { First }_{i}+\beta_{5} \text { Second }_{i}+\beta_{6} P C M_{i} \times \text { First }_{i}+\beta_{7} P C M_{i} \times \text { Second }_{i}+ \\
\beta_{8} \text { Power }_{i} \times \text { First }_{i}+\beta_{9} \text { Power }_{i} \times \text { Second }_{i}+\beta_{10} \text { PCM }_{i} \times \text { Power }_{i} \times \text { First }_{i}+\beta_{11} P C C M_{i} \times \text { Power }_{i} \times \text { Second }_{i}+\varepsilon_{i j}, e_{i} \sim N\left(0, \sigma_{1}^{2}\right)\end{array}$} \\
\hline & Estimate & Std. Error & Degrees of Freedom & $\mathrm{H}_{\mathrm{a}}$ & t-statistic & \\
\hline \multicolumn{7}{|l|}{ Whole Day } \\
\hline$\mu$ & 171.93 & 86.58 & 824 & $\boldsymbol{\mu} \neq \mathbf{0}$ & 1.99 & 0.0474 \\
\hline PCM & 26.94 & 122.56 & 12 & $\beta_{1} \neq 0$ & 0.22 & 0.8297 \\
\hline Power & -44.60 & 122.58 & 12 & $\beta_{2} \neq \mathbf{0}$ & -0.36 & 0.7223 \\
\hline PCM $\times$ Power & 304.94 & 174.79 & 12 & $\beta_{3} \neq 0$ & 1.74 & 0.1066 \\
\hline First & -229.16 & 15.72 & 824 & $\beta_{4} \neq 0$ & -14.58 & $<.0001$ \\
\hline Second & -83.79 & 15.72 & 824 & $\beta_{5} \neq 0$ & -5.33 & $<.0001$ \\
\hline PCM $\times$ First & 168.75 & 21.27 & 824 & $\beta_{6} \neq 0$ & 7.93 & $<.0001$ \\
\hline $\mathrm{PCM} \times$ Second & 78.82 & 21.27 & 824 & $\beta_{7} \neq 0$ & 3.71 & 0.0002 \\
\hline Power $\times$ First & 146.35 & 23.20 & 824 & $\beta_{8} \neq 0$ & 6.31 & $<.0001$ \\
\hline Power $\times$ Second & 85.44 & 23.20 & 824 & $\beta_{9} \neq 0$ & 3.68 & 0.0002 \\
\hline PCM $\times$ Power $\times$ First & -350.28 & 39.14 & 824 & $\beta_{10} \neq 0$ & -8.95 & $<.0001$ \\
\hline PCM $\times$ Power $\times$ Second & -124.61 & 39.14 & 824 & $\beta_{11} \neq 0$ & -318 & 0.0015 \\
\hline \multicolumn{7}{|c|}{$\begin{array}{c}\text { PriceInc }_{i j}-\text { PriceInc }^{t}=\mu+e_{i}+\beta_{1} \text { PCM }_{i}+\beta_{2} \text { Power }_{i}+\beta_{3} \text { PCM }_{i} \times \text { Power }_{i}+\beta_{4} \text { First }_{i}+\beta_{5} \text { Second }_{i}+\beta_{6} \text { PCM }_{i} \times \text { First }_{i}+\beta_{7} \text { PCM }_{i} \times \text { Second }_{i}+ \\
\beta_{8} \text { Power }_{i} \times \text { First }_{i}+\beta 9 \text { Power }_{i} \times \text { Second }_{i}+\beta_{10} \text { PCM }_{i} \times \text { Power }_{i} \times \text { First }_{i}+\beta_{11} \text { PCM }_{i} \times \text { Power }_{i} \times \text { Second }_{i}+\varepsilon_{i,}, e_{i} \sim N\left(0, \sigma_{l}^{2}\right) \text { and } \varepsilon_{i j} \sim N\left(0, \sigma_{2, i}^{2}\right)\end{array}$} \\
\hline \multicolumn{7}{|c|}{ Whole Day } \\
\hline $\boldsymbol{\mu}$ & 871.79 & 132.26 & 824 & $\mu \neq 0$ & 6.59 & 0.0001 \\
\hline PCM & 44.12 & 187.51 & 12 & $\beta_{1} \neq 0$ & 0.24 & 0.8180 \\
\hline Power & -89.36 & 187.56 & 12 & $\beta_{2} \neq 0$ & -0.48 & 0.6423 \\
\hline PCM $\times$ Power & -376.89 & 266.66 & 12 & $\beta_{3} \neq 0$ & -1.41 & 0.1830 \\
\hline First & -82.44 & 36.28 & 824 & $\beta_{4} \neq 0$ & -2.27 & 0.0233 \\
\hline Second & 113.41 & 36.28 & 824 & $\beta_{5} \neq 0$ & 3.13 & 0.0018 \\
\hline PCM $\times$ First & 65.34 & 56.83 & 824 & $\beta_{6} \neq 0$ & 1.15 & 0.2506 \\
\hline $\mathrm{PCM} \times$ Second & -121.53 & 56.83 & 824 & $\beta_{7} \neq 0$ & -2.14 & 0.0328 \\
\hline Power $\times$ First & -255.34 & 55.26 & 824 & $\beta_{8} \neq 0$ & -4.62 & $<.0001$ \\
\hline Power×Second & -108.16 & 55.26 & 824 & $\beta_{9} \neq 0$ & -1.96 & 0.0506 \\
\hline PCM $\times$ Power $\times$ First & 317.92 & 87.31 & 824 & $\beta_{10} \neq 0$ & 3.64 & 0.0003 \\
\hline PCM $\times$ Power $\times$ Second & 123.33 & 87.31 & 824 & $\beta_{11} \neq 0$ & 1.41 & 0.1582 \\
\hline
\end{tabular}


These findings suggest that fixed start-up fees are used quite strategically. As a consequence the sellers in the No Power treatments are able to extract the same amount of wealth as in the Power treatments. These anticompetitive effects of offer complexity seem to be dominating the expected effects of the optimization algorithms and market structure.

Finding 4. High buyer prices in the No Power treatments are the result of heightened offers on both start-up fee and seller price dimensions. Sellers in both auctions earn similar daily income from fees and seller prices.

Table 4 presents a mixed-effects model for the income from fees and for the income from seller prices. The dependent variable in this case is the difference between the observed income from fees (seller prices), FeeInc (PriceInc), and the income from fees (seller prices) when production costs are perfectly revealed by the sellers, FeeInc ${ }^{t}\left(\right.$ PriceInc $\left.^{t}\right)$. The estimates from the model point out that the sellers receive significantly higher incomes than in the true cost revelation outcome by increasing offers on both fees and seller prices. In the OCM/No Power treatment, daily amount of fees exceeds true start-up costs by 171.9 ( $p$-value $=0.0474$ ) and price income surpasses variable costs by 871.8 ( $p$-value $<0.0001)$. The respective estimates for the PCM/No Power treatment are 198.9 ( $p$-value=0.0221) and 915.9 ( $p$-value $<0.0001)$. The estimates for the PCM/No Power treatment do not significantly differ from the OCM/No Power treatment (fee income $p$-value $=0.8297$; price income $p$-value $=0.8180$ ).

Finding 4 highlights that market participants exploit both fees and seller prices to increase profits in a complex-offer auction. In Table 4, the significant coefficients for early periods (e.g. First, Second, PCM $\times$ First etc.) also show that the sellers are actively adjusting their offer strategies for fees and prices over time.

Findings 3 and 4 might be an explanation why ISOs try limiting frequent offer changes for start-up fees, while remaining faithful to the unregulated nature of the seller prices. The effects of such restrictions are still to be evaluated.

Finding 5. Ceteris paribus, changing the auction institution from OCM to PCM does not significantly reduce production efficiency in any period.

Figures 7-10 illustrate the realized ATC in the market for all periods of a day. Table 5 summarizes the results of the Mann-Whitney U test comparing the ATC in the OCM auction and the PCM auction. The evidence suggests that the PCM auction is at least as efficient as the OCM auction in all periods. In peak periods of the No Power treatment, the PCM auction has significantly better production efficiency than the OCM auction (one-tailed $p$-value $=0.0286$ ). The OCM auction's performance in peak periods is worsened by the successful sales of very high cost generators $\mathrm{H}$ and I. These generators are selected in peak periods and make positive profits for 42 (4) times [out of possible $68=17$ days $\times$ 4sessions] in the OCM/No Power (/Power) treatment and for 6 (28) times in the PCM/No Power (/Power) treatment. H and I plants make significant profits by offering low seller prices and recovering their variable costs through high start-up fees. Note that these plants would never sell profitably if they had to recover their costs only through seller prices.

Table 5. Mann-Whitney $\mathrm{U}$ test on the average total production costs for the last 17 market days

\begin{tabular}{lcccc}
\hline & \multicolumn{2}{c}{$\begin{array}{c}\text { OCM/No Power vs. } \\
\text { PCM/No Power }\end{array}$} & \multicolumn{2}{c}{$\begin{array}{c}\text { OCM/Power vs. } \\
\text { PCM/Power }\end{array}$} \\
\cline { 2 - 5 } \multicolumn{1}{c}{ Period } & $\mathrm{U}_{4,4}$ & $\mathrm{p}$ (two-tailed) & $\mathrm{U}_{4,4}$ & $\mathrm{p}$ (two-tailed) \\
\hline Off peak & 12 & 0.3429 & 9 & 0.8857 \\
Shoulder 1 & 10 & 0.6857 & 13 & 0.2000 \\
Peak & 15 & 0.0571 & 10 & 0.6857 \\
Shoulder 2 & 8 & 1.0000 & 8 & 1.0000 \\
\hline
\end{tabular}

a) Since the Power treatments failed to transact equilibrium quantities on a significant number of occasions, the comparison of realized ATCs is limited.

Finding 5 does not confirm an expectation that the OCM auction would be more likely to elicit outcomes that are more production efficient. The fact that the more efficient plants are unsuccessful in competing with the high cost plants is also surprising since all sellers could use similar strategies. My guess is that there is incomplete information about the returns in the market. Sellers simply do not know that they could be earning more. While the seller prices are publicly announced in the market, the collected individual start-up fees are not known to other sellers. Perhaps, the lack of transparency in earnings rather than production costs weakens the performance of these complex-offer auctions regarding to production efficiency.

Finding 6. Ceteris paribus, shoulder 2 periods are more competitive than shoulder 1 periods regardless of the auction.

The demand and supply structures during the shoulder 1 and 2 periods are identical. Therefore, the equilibrium quantities are too. The OCM and the PCM auctions always transact competitive equilibrium amounts in shoulder 2 
periods, but as mentioned above, they come short in number occasions during shoulder 1 periods in both No Power and Power treatments.

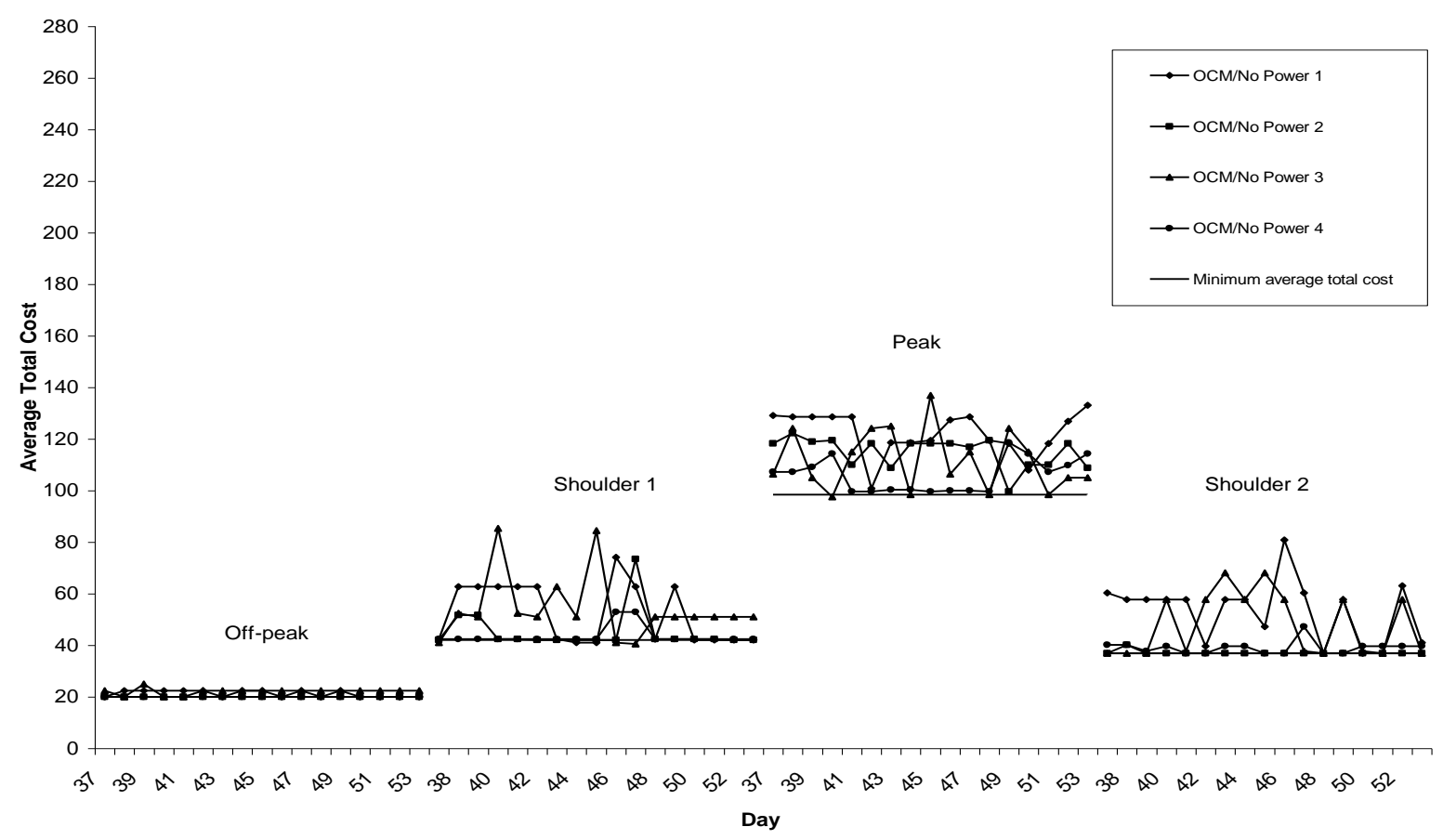

Figure 7. OCM/No Power Average total costs by level of demand for the last 17 market days in each session

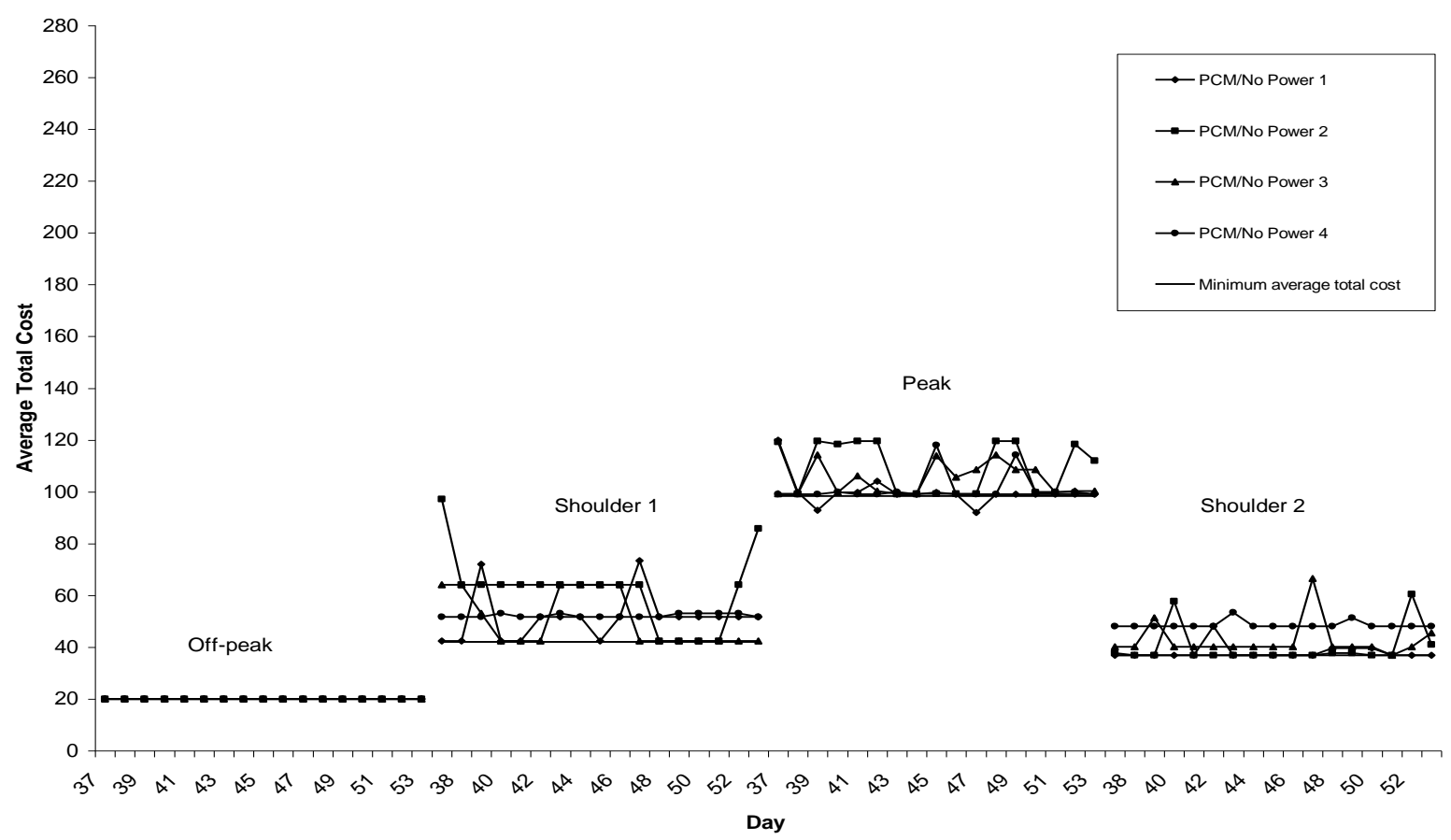

Figure 8. PCM/No Power Average total costs by level of demand for the last 17 market days in each session 


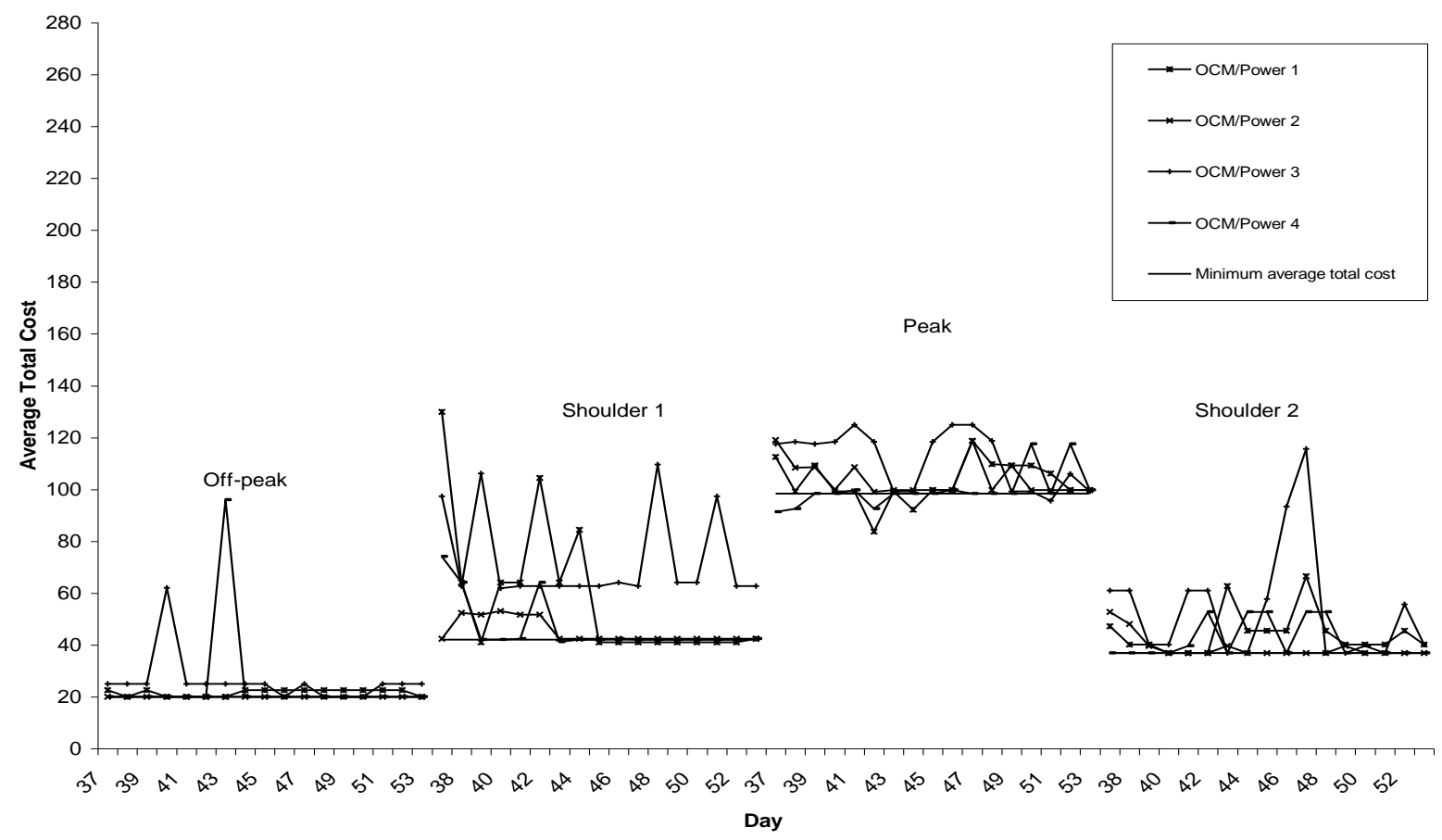

Figure 9. OCM/Power Average total costs by level of demand for the last 17 market days in each session

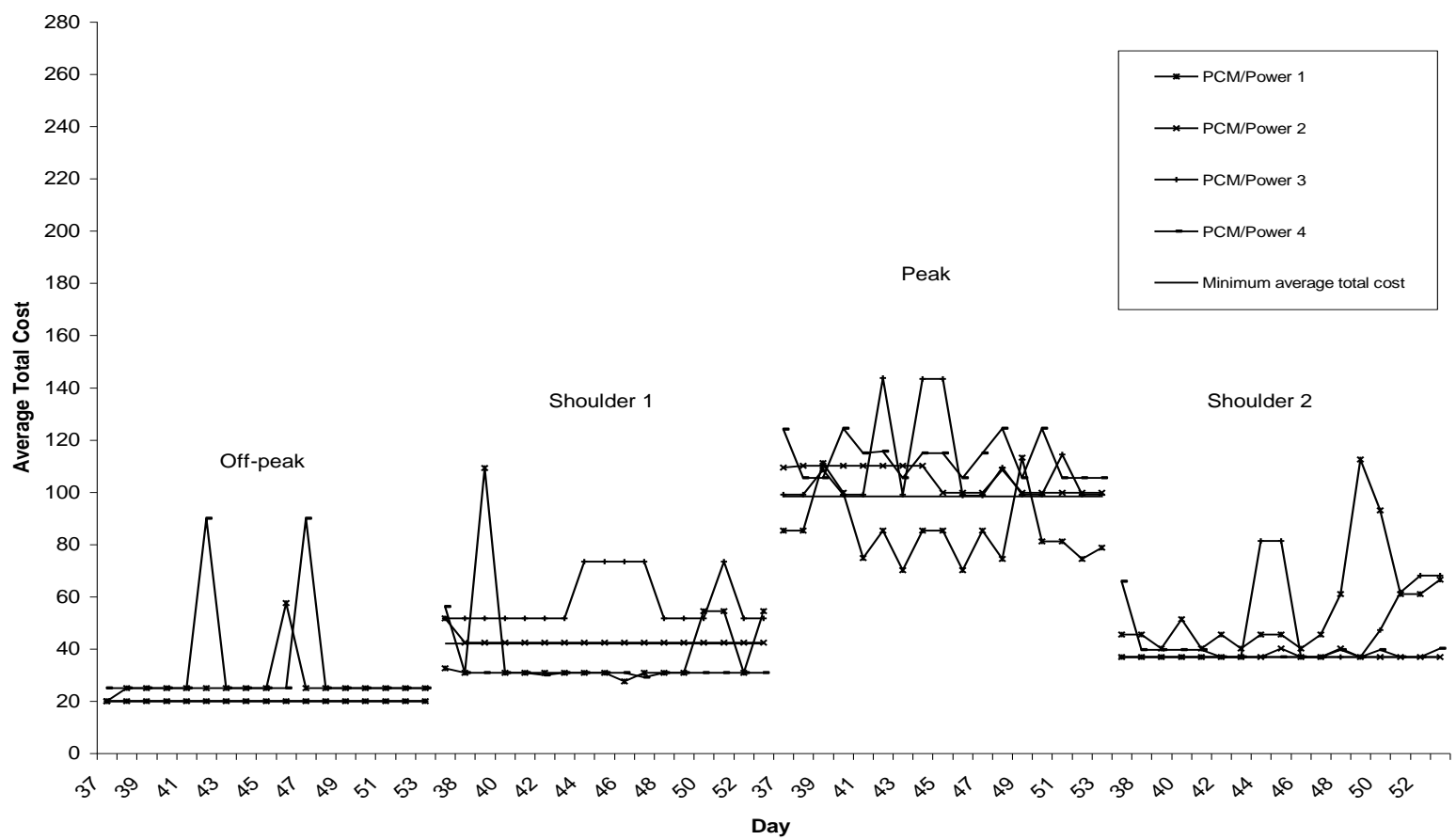

Figure 10. PCM/Power Average total costs by level of demand for the last 17 market days in each session

Buyer prices in shoulder 2 periods are not significantly different from the prices corresponding to the true cost revelation. On the other hand, the OCM/No Power (PCM/No Power) treatment significantly raises prices above the true cost revelation level by 18.53 ( $p$-value $=0.0108$ ) [17.08 ( $p$-value $=0.0368)$ ] in shoulder 1 periods.

Average economic profits of the marginal plants are lower in shoulder 2 compared to shoulder 1 periods (Figure 6 ). The 
Mann-Whitney $\mathrm{U}$ test suggests that differences are significant in both the OCM/No Power and the PCM/No Power treatments (one-tailed $p$-values $=0.0571,0.1000$ ).

The need to shut down plants after the peak periods and ineligibility of sellers for start-up fees clearly promotes more competitive behavior. When sellers compete purely on prices they are more likely to approach the true cost revelation outcome. The absence of avoidable fixed costs in shoulder 2 periods has a significant influence on behavior in the market. The question beyond the scope of this paper is if these relatively competitive outcomes could be attained in a market with a cyclical demand and avoidable start-up costs while the sellers are not allowed to charge fixed start-up fees.

\section{Discussion and Conclusion}

In a dynamic trading environment that models wholesale electric power markets, the OCM and the PCM auctions do not exhibit significant differences in procurement cost and efficiency.

Game theory predicts that in a competitive environment with static demand the marginal generators should submit offers that are equal to their actual production costs. The findings of the experiment indicate that the marginal plants do not reveal their actual production costs when demand is cyclical in either auction. Such bidding behavior is a warning to policy makers who consider various non-convex market-clearing algorithms and receive recommendations that rely on the assumption of true cost revelation.

A surprising finding is that buyer prices in the No Power treatments approach the prices of the Power treatments. It appears that the expected institutional effects on procurement cost and efficiency are greatly dominated by the effects of strategic behavior due to the complex offers. Incentives to start-up plants during the higher demand periods and the ability to sell high cost units by manipulating combinations of offered fees and prices have strong anti-competitive effects. Interestingly, investing in cheap generation capacity would not reduce these anti-competitive effects as the new plants would have same incentives to withhold their start-ups for higher demand periods.

On the other hand, the outcomes during shoulder 2 periods are noticeably more competitive and efficient than any other period. The need to shut down some plants (instead of starting them up) after the peak periods and ineligibility of sellers for start-up fees undoubtedly affects bidding behavior. It leaves a person wondering how simpler and more transparent these markets could be if avoidable fixed costs did not exist - but they do. However, allowing the sellers to recover their fixed and variable costs separately might not be the best recipe to promote transparency and competition in markets with non-convex production technologies. I hope to see this issue being better addressed in future work.

\section{Acknowledgements}

I thank the National Science Foundation under grants ECS-0323685 and SES-0648937 and the International Foundation for Research in Experimental Economics for financial support of this research. Acknowledgements are extended to Vicki Knoblauch, Peter Luh, Stephen Rassenti, Vernon Smith, Bart Wilson and seminar participants at the University of Connecticut, George Mason University, Economic Science Association Meetings, Southern Economic Association Meetings and the State Seminar at the Institute for Regulatory Law and Economics for their comments, Jeffrey Kirchner for his superb programming, Feng Zhao and William Blankson for their able research assistance.

\section{References}

Alonso, J., Trias, A., Gaitan, V., \& Alba, J. (1999). Thermal plant bids and market clearing in an electricity pool. Minimization of costs vs. minimization of consumer payments. IEEE Transactions on Power Systems, 14(4), 1327-1334. http://dx.doi.org/10.1109/59.801892

Arroyo, J., \& Conejo, A. (2002). Miltiperiod auction for a pool-based electricity market. IEEE Transactions on Power Systems, 17(4), 1225-1231. http://dx.doi.org/10.1109/TPWRS.2002.804952

Baltaduonis, R. (2007). Efficiency in deregulated electricity markets: offer cost minimization vs. payment cost minimization auction. In J. Roufagalas (Ed.), Mechanisms \& Policies in Economics (pp.173-188). Athens, Greece: ATINER.

Davis, D., \& Holt, C. (1994). Market power and mergers in laboratory markets with posted prices. RAND Journal of Economics, 25(3), 467-487.

Durham, Y., McCabe, K., Olson, M., Rassenti, S., \& Smith, V. (2004). Oligopoly competition in fixed cost environments. International Journal of Industrial Organization, 22, 147-162. http://dx.doi.org/10.1016/j.jijindorg.2003.06.002

Durham, Y., Rassenti, S., Smith, V., Van Boening, M., \& Wilcox, N. (1996). Can core allocations be achieved in avoidable fixed cost environments using two-part price competition? Annals of Operations Research, 68, 61-88. http://dx.doi.org/10.1007/BF02205449

Energy Information Administration. (2013). Electric power sales, revenue, and energy efficiency Form EIA-861 
detailed data files. Retrieved from http://www.eia.gov/electricity/data/eia861

Holt, C. (1989). The exercise of market power in laboratory experiments. Journal of Law and Economics, 32, S107-S130. http://dx.doi.org/10.1086/467190

Knoblauch, V. (2005). Can a newly proposed mechanism for allocating contracts in U.S. electricity wholesale markets lead to lower prices? A game theoretic analysis. Working Papers 2004-41R, University of Connecticut, Department of Economics. http://www.econ.uconn.edu/working/2004-41r.pdf

Luh, P., Blankson, W., Chen, Y., Yan, J., Stern, G., Chang, S., \& Zhao, F. (2006). Payment cost minimization auction for deregulated electricity markets using surrogate optimization. IEEE Transactions on Power Systems, 21(2), 568-578. http://dx.doi.org/10.1109/TPWRS.2006.873104

O’Neill, R., Sotkiewicz, P., Hobbs, B., Rothkopf, M., \& Stewart Jr., W. (2004). Efficient market-clearing prices in markets with nonconvexities. European Journal of Operational Research, 164(1), 269-285. http://dx.doi.org/10.1016/j.ejor.2003.12.011

Padhy, N. (2004). Unit commitment - a bibliographical survey. IEEE Transactions on Power Systems, 19(3), 1196-1205. http://dx.doi.org/10.1109/TPWRS.2003.821611

Rassenti, S., Smith, V., \& Wilson, B. (2003a). Controlling market power and price spikes in electricity networks: demand side-bidding. Proceedings of the National Academy of Sciences, 100(5), 2998-3003. http://dx.doi.org/10.1073/pnas.0437942100

Rassenti, S., Smith, V., \& Wilson, B. (2003b). Discriminatory price auctions in electricity markets: low volatility at the expense of high price levels. Journal of Regulatory Economics, 23(2), 109-123. http://dx.doi.org/10.1023/A:1022250812631

Yan, J., \& Stern, G. (2002). Simultaneous optimal auction and unit commitment for deregulated electricity markets. The Electricity Journal, 72-80. http://dx.doi.org/10.1016/S1040-6190(02)00380-9

Zhao, F., Luh, P.; Yan, J.; Stern, G.; \& Chang, S. (2010). Bid cost minimization versus payment cost minimization: a game theoretic study of electricity auctions. IEEE Transactions on Power Systems, 25(1), 181-194. http://dx.doi.org/10.1109/TPWRS.2009.2036824

\section{Notes}

Note 1. For a bibliographical survey on the unit commitment problem see Padhy (2004).

Note 2. For a discussion on mechanisms for markets with non-convexities that is motivated by electric power markets see O'Neill, Sotkiewicz, Hobbs, Rothkopf, and Stewart Jr. (2004).

Note 3. Same as in Rassenti et al. (2003a; 2003b) and Durham et al. (1996).

Note 4. For an experimental investigation of uniform versus discriminatory price auctions see Rassenti et al. (2003b).

Note 5. See Appendix A for a simple numerical example that demonstrates the principles of offer-selection rules for the OCM and the PCM auctions.

Note 6. See Appendix A for a simple example demonstrating creation of unilateral market power.

Note 7. I originally planned to have 60 trading days per session. However, the first conducted session was interrupted by the computer network failure after the 53rd day. Since the data from that first session suggested that the bidding behavior in the market stabilized around the 35th day, I decided to shorten the rest of the sessions to 53 days as well.

Note 8. The chosen time frame is similar to one-minute trading days of the Rassenti et al. (2003a; 2003b) electric power experiments and $75 \mathrm{~s}$ trading days of Durham, McCabe, Olson, Rassenti, and Smith (2004) experiment.

Note 9. ISOs usually demand an explanation if generators change their offered generation capacity or technical constraints. Thus strategic behavior is somewhat limited with regards to these parameters of an offer.

Note 10. I am aware that there are various initiatives to regulate start-up cost reimbursement (e.g. limiting the ability to change the start-up fees freely; and partial start-up cost reimbursement) for electric power generators in naturally occurring markets. However, the purpose of the study is to investigate the performance of the two auctions when such interventions into a deregulated market are absent.

Note 11. See Appendix B for the experimental instructions and Appendix C for an example of a subject screen during the experiment.

Note 12. The p-values for the PCM/No Power treatment are based on the linear mixed-effects model where the benchmark treatment is $P C M /$ No Power. These estimates parallel the estimates reported in table 3 . 
Note 13. Since at least one unit has to be picked from $S 1$ during the off-peak of the Power treatment, the PCM auction adds a MCP and a start-up fee to the payment if the second unit is supplied by $S 3$ and only a MCP if the second unit comes from $S 1$. This effectively eliminates $S 3$ from the off-peak competition. Therefore, $S 1$ is guaranteed to supply two units regardless of her price offer (unless $S 1$ and $S 3$ ask for zero start-up fees). Hence, the unilateral market power during the off-peak is even stronger in the PCM/Power treatment. On the other hand, the OCM auction computes MCPs after allocating contracts. That helps $S 3$ to stay in the competition in the OCM/Power treatment. But it is still surprising that buyer prices in the $O C M / N$ o Power treatments approach levels of the OCM/Power treatments.

Note 14. The linear mixed-effects model is fit by maximum likelihood with 848 original observations and 16 sessions. For purposes of the brevity the session random effects are not included in the table.

\section{Appendix A}

\section{An Example of a Simple Wholesale Electricity Market}

To highlight the differences of the market-clearing rules in question, consider a three-supplier market examined by Knoblauch (2005) and Baltaduonis (2007). Say we have an electricity market for one hour. The demand is inelastic and equals to 2 units. Supplier $1(S 1)$ and Supplier $2(S 2)$ are identical. They incur 6 dollars of fixed costs to start up their plants and 93 dollars of variable costs to generate one unit of electricity. Each of them can supply 0, 1 or 2 units of electricity. Supplier 3 (S3) has start-up cost of 20 dollars and variable cost of 70 dollars per unit. She can supply 0 or 1 unit of electricity.

For the purpose of this example suppose that all suppliers submit offers that reflect their true production costs.

\section{A.1 The OCM Auction}

The OCM algorithm minimizes the total offered cost of electricity, as if all selected sellers would be paid their offered prices and fees. Given the offers, an ISO calculates the minimum offered cost in two cases: 1) buying 2 units from $S 1(S 2)$, OR 2) buying 1 unit from $S 3$ and 1 unit from $S 1(S 2)$ :

$$
\begin{gathered}
\text { Min }\left\{\text { Price }_{1,2} \times 2+\text { Fee }_{1,2}, \text { Price }_{3}+\text { Fe }_{3}+\text { Price }_{1,2}+\text { Fee }_{1,2}\right\}, \\
\text { Min }\{93 \times 2+6,70+20+93+6\}=70+20+93+6=189 .
\end{gathered}
$$

The auction chooses to buy 1 unit from $S 3$ and 1 unit from $S 1(S 2)$. After the offers are selected, a uniform MCP is determined as the highest accepted price for that period; the MCP is $93(=\max \{70,93\})$. All selected sellers receive their individual start-up fees and the uniform MCP for the supplied electricity during that period; the total procurement cost of electricity is $212(=93 \times 2+20+6)$. The uniform market price that all buyers pay is $106[=93+(20+6) \div 2)]$. Notice that this contract allocation is production efficient, since there is no way to generate 2 units of electricity cheaper than the chosen suppliers do.

\section{A.2 The PCM Auction}

The PCM algorithm minimizes the actual procurement cost of electricity, simultaneously determining a MCP as the highest accepted price during that period. An ISO calculates the minimum procurement cost in two cases: 1) buying 2 units from $S 1(S 2)$, OR 2) buying 1 unit from $S 3$ and 1 unit from $S 1(S 2)$ :

$$
\begin{gathered}
\text { Min }\left\{\text { Price }_{1,2} \times 2+\text { Fee }_{1,2}, \max \left\{\text { Price }_{3}, \text { Price }_{1,2}\right\} \times 2+\text { Fee }_{3}+\text { Fee }_{1,2}\right\}, \\
\operatorname{Min}\{93 \times 2+6, \max \{70,93\} \times 2+20+6\}=93 \times 2+6=192 .
\end{gathered}
$$

The auction chooses to buy 2 units from $S 1(S 2)$. The MCP is 93 . As in the OCM auction, the selected sellers receive their individual start-up fees and the uniform MCP for the supplied electricity. Both the total procurement cost and the total production cost are equal to $192(=93 \times 2+6)$. The market price for buyers is $96(=93+6 \div 2)$. This contract allocation is not production efficient since $S 3$ 's plant with relatively lower average total cost is idle.

\section{A.3 Creating Unilateral Market Power}

Transferring two of $S 2$ 's capacity units to $S 1$ would undoubtedly create unilateral market power in an effective duopoly. $S 1$ would be guaranteed to supply at least one unit to the market. She could unilaterally bid up the price for her unit and earn a significant profit as long as the market demand is perfectly inelastic. If $S 1$ submitted a low offer with the hope to supply two units to the market she would risk losing her guaranteed profit. In this case, offering the capacity at high prices and/or start-up fees is a dominant strategy for $S 1$.

\section{Appendix B}

Experimental Instructions

<page 1>

This is an experiment in the economics of decision-making. If you read the instructions carefully and make good decisions, you may earn a considerable amount of money that will be paid to you in CASH at the end of the experiment.

The experiment will take place through the computer terminals at which you are seated. If you have any questions at any time, 
please raise your hand and a monitor will come to assist you.

In this experiment, owners of plants sell an identical product to a computer buyer every day. Each day lasts 75 seconds. You are an owner of \#yourNumberOfPlants\# plants. There are \#numberOfSellers\# sellers and \#numberOfPlants\# plants including yours. Each seller owns between 1 and 4 plants.

<page 2>

Each day is divided into 4 quarters. Each quarter is represented by a line in the table at the top of your screen. The computer will purchase varying quantities of the product over the course of a day: Low, Medium, High and Medium amounts.

Sellers submit offers to sell. An offer indicates the prices and quantities of the product that you are willing to sell during the course of the following day. All quantities are measured in number of units.

<page 3>

You as a seller are able to decide:

Price/unit is the price per unit you are willing to sell at during that quarter from that plant. This is the minimum price at which you are willing to sell. The actual market price may be higher depending on the demand of the product. Each seller receives the same market price for sold units during the quarter. The market price is the highest accepted Price/unit among all of the sellers. If you sell the product you also incur a cost per unit sold. This cost is listed on the right side under the table and must be paid for each unit you sell.

Start-Up Fee is a fee that is paid to you for turning on your plant. The fee is paid to you only if the plant was not operating during the previous quarter. When your plant is turned on, you also must pay the start-up cost, which is listed on the right side under the table.

You will be able to make this decision for each quarter of the upcoming day for each plant that you have. <page 4>

To switch between plants click on the tabs at the top of your screen. To enter the values select the appropriate cell in the table and double click.

Some offer values are automatically filled in for you:

Min Qty is the minimum number of units you are willing to sell during that quarter from that plant. Min Qty must be $\geq$ Minimum Capacity, which is specified under the table. This will be filled with that plant's Minimum Capacity.

Max Qty is the maximum number of units you are willing to sell during that quarter from that plant. Max Qty must be $\leq$ Maximum Capacity, which is specified under the table. Max Qty must also be $\geq$ Min Qty. This will be filled with that plant's Maximum Capacity.

<page 5 PCM>

Offers are sent to the computerized market coordinator when you click the Submit button or when the day is over. Your offer from the previous day will be automatically submitted for you if you choose not to make any changes during the course of a day.

The computerized market coordinator accepts those offers that satisfy the market demand during the day at the lowest total procurement cost, simultaneously determining the market price as the highest accepted Price/unit for that quarter.

If your offer has not been accepted, it means that other offers were able to satisfy the market demand at a lower or equal cost. The results are displayed on the right side of the table; you may need to scroll to the right to see them. Once you have reviewed the results of the previous day enter your offers for the next day for each plant and submit.

The right side of the table is filled in after everyone has submitted their offers.

Your profit during each quarter of a day is:

$($ Units Sold $\times$ market price + Start-Up Fees collected $)-($ Units Sold $\times$ Cost/unit + Start-Up Costs incurred $)$

<page 5 OCM>

Offers are sent to the computerized market coordinator when you click the Submit button or when the day is over. Your offer from the previous day will be automatically submitted for you if you choose not to make any changes during the course of a day.

The computerized market coordinator accepts those offers that satisfy the market demand during the day at the lowest total offered cost. After the offers are selected, the market price is determined as the highest accepted Price/unit for that quarter.

If your offer has not been accepted, it means that other offers were able to satisfy the market demand at a lower or equal cost. The results are displayed on the right side of the table; you may need to scroll to the right to see them. Once you have reviewed the results of the previous day enter your offers for the next day for each plant and submit.

The right side of the table is filled in after everyone has submitted their offers.

Your profit during each quarter of a day is: 
$($ Units Sold $\times$ market price + Start-Up Fees collected $)-($ Units Sold $\times$ Cost/unit + Start-Up Costs incurred $)$ <page 6>

A history of the prices from the past 10 days and the sold quantities during each quarter of the last day are displayed in the bottom portion of your screen.

Information about all plants (including yours) is available to all sellers by clicking on the Technology and costs button.

Plants are restarted at the beginning of each day, meaning that during the first quarter of each day you receive your start-up fee and incur the start-up cost if you sell the product.

At the end of today's session, your 'computer dollars' will be converted into cash at a rate of \#exchangeRate\# computer dollars to US\$1. If you have any questions please raise your hand. Press Start when you are ready to begin.

Even if you decide to keep your offer from the previous day, click the Submit button. The experiment will advance to the next day after everyone has clicked on the Submit button.

\section{Appendix C}

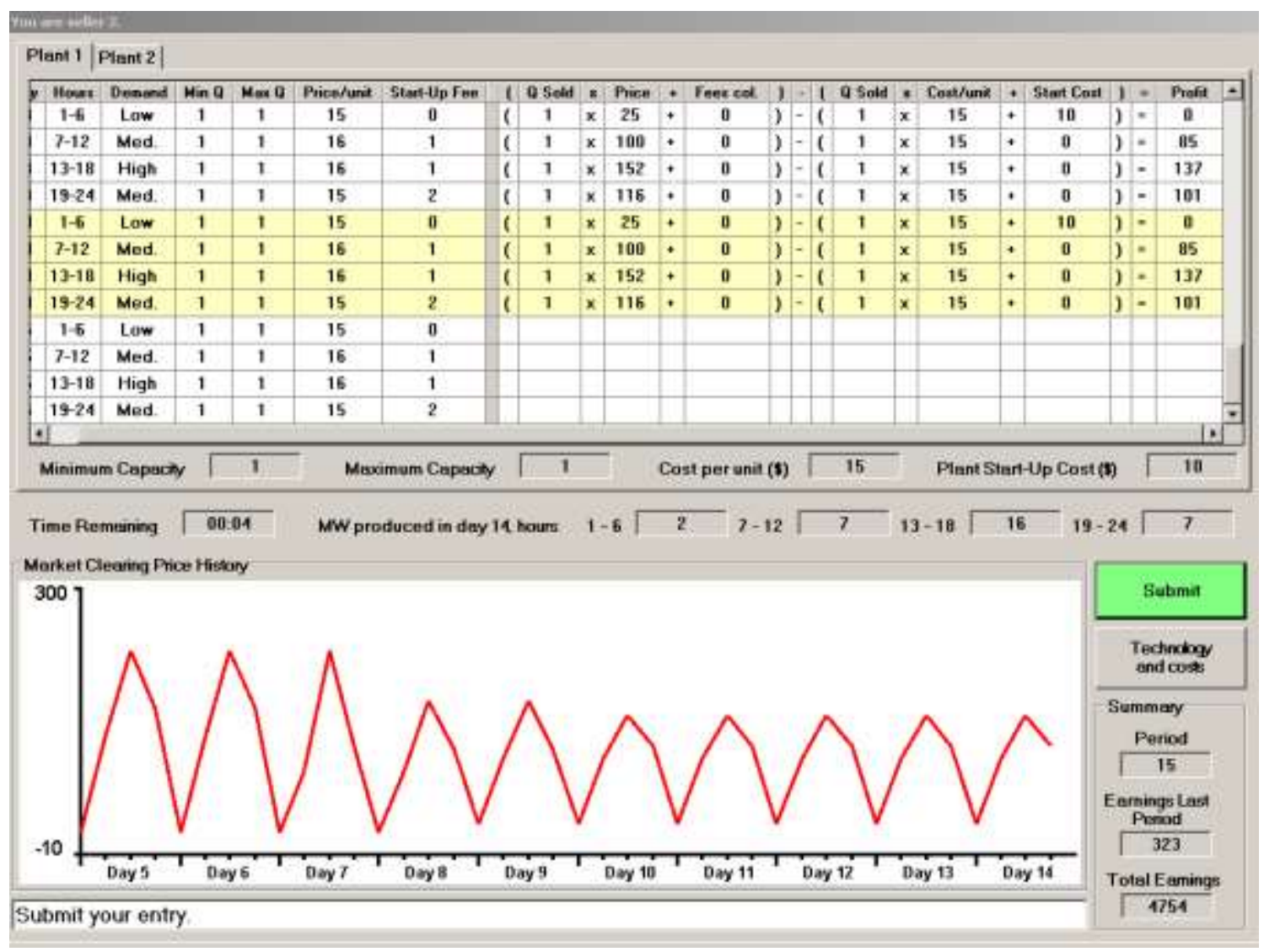

Figure C1. Sample screen shot

\section{(cc) $\mathrm{EY}$}

This work is licensed under a Creative Commons Attribution 3.0 License. 